\title{
Huata: aproximaciones cronológicas y arquitectónicas de un asentamiento ubicado en el Alto Marañón (Huánuco)
}

\author{
Huata: chronological and architectural approaches of a settlement \\ located in the Upper Marañón (Huánuco)
}

\author{
Jakeline Romero Rodríguez \\ https://orcid.org/0000-0003-3681-0390 \\ Universidad Nacional Mayor de San Marcos \\ jakelineromero787@gmail.com \\ Katia Herrera Ynderique \\ https://orcid.org/0000-0002-0905-0819 \\ Universidad Nacional Mayor de San Marcos \\ katiaherrera0128@gmail.com
}

\section{RESUMEN}

El sitio arqueológico Huata se ubica en el área conocida como el Alto Marañón (Huánuco), y tiene breves referencias en la literatura arqueológica de la región. Por ello, una forma de aproximarnos a su estudio fue caracterizando su cronología y arquitectura a partir del análisis de las estructuras expuestas, la comparación con otros sitios de la zona, en especial Rapayán (Áncash) y Piruro (Huánuco), y la revisión de una visita de Miguel de La Serna y Juan de Espinosa del año 1549. En conclusión, se trata de un sitio con ocupaciones desde el Intermedio Tardío hasta inicios del Período colonial, proceso histórico que se ve reflejado en las estructuras. Finalmente, la particular configuración arquitectónica y espacial sugiere una organización dual, característica de algunos grupos sociales que ocuparon los Andes Centrales.

Palabras clave: Huata, Alto Marañón, arquitectura, cronología. 


\section{ABSTRACT}

Huata is an Archaeological Site located in the area known as Alto Marañón (Huánuco), and has brief references in the archaeological publications. Therefore, a way to approach its study was to characterize its chronology and architecture based on the analysis of the exposed structures, defining its typology, a comparative study will make with other sites in the area, especially Rapayán (Áncash) and Piruro (Huánuco); in addition, a review of the visit of Miguel de La Serna and Juan de Espinosa in 1549 will make. Consequently, this is a site with occupations from the Late Intermediate to the early Colonial Period, a historical process evidenced in the variability of its structures. Finally, the particular architectural and spatial configuration would suggest a dual organization, a recurrent characteristic of some social groups that occupied the Central Andes.

Keywords: Huata, Upper Marañón, architecture, chronology.

ReCibido: 08/07/2021 - Aceptado: 09/09/2021 - Publicado: 25/11/2021

\section{INTRODUCCIÓN}

El área conocida como el Alto Marañón ha sido definido arqueológicamente a partir de sus monumentales restos arquitectónicos, elementos diagnósticos que han servido a los investigadores para afirmar que fue ocupado por la cultura Tantamayo (Flornoy, 1957), el Imperio yaro (Amat, 2013) o los wamallí (Salcedo, 2012); otros estudiosos, a partir de la revisión de fuentes documentales, indican que fue habitado por los guanucos (Varallanos, 1959); pero hasta el día de hoy no hay consenso. Para los fines de este trabajo es innecesario entrar en dicho debate, ya que interesa más caracterizar los aspectos del orden cronológico y arquitectónico, a partir del estudio de uno de los asentamientos.

Las investigaciones más importantes realizadas en la zona se han enfocado en los valles de Rapayán (Áncash) y Tantamayo (Huánuco), las cuales arrojaron datos sobre la cronología, arquitectura, patrón de asentamiento, entre otros. Pese a estos esfuerzos, no se puede generalizar los resultados para toda el área del Alto Marañón, por ello, está por definirse aún la cronología, debido a que existen sitios con una ocupación larga y continua, pero quedan dudas sobre otros. Caso similar ocurre con la arquitectura, donde se observa una variabilidad de formas y técnicas constructivas que llevan a cuestionar si el Alto Marañón fue ocupado por una sola gran cultura durante el período tardío. 0 , por el contrario, probablemente habría servido de escenario para pequeños grupos sociales. 


\section{OBJETIVO Y METODOLOGÍA}

Este primer estudio exploratorio tiene como objetivo realizar una aproximación cronológica y arquitectónica del sitio arqueológico Huata, con la finalidad de entender los procesos sociales de los grupos culturales pertenecientes a la región del Alto Marañón.

Para el desarrollo de esta investigación se ha utilizado el método inductivo, que parte del análisis de las estructuras expuestas en el sitio, haciendo uso de la prospección superficial entendida como "la técnica arqueológica de campo consistente en la exploración visual del registro material conservado en la superficie del terreno y su debida documentación mediante un método planificado y atendiendo a unos objetivos concretos" (Cerrato, 2011, p. 151). Sitios como Huata, pertenecientes a periodos tardíos y ubicados en las cumbres de los cerros se encuentran en regular estado de conservación; dicha arquitectura expuesta permite obtener gran cantidad de información para responder a estudios de planificación del espacio construido, tipos de arquitecturas, diseños y técnicas constructivas, características que obedecen a indicadores de una complejidad social.

El estudio del sitio se ejecutó en dos etapas: la primera, consistió en el trabajo de revisión de las principales fuentes de literatura arqueológica y etnohistórica del Alto Marañón, así como la revisión de imágenes satelitales del área de estudio; en la segunda, se realizó el trabajo de campo, que se ha desarrollado en dos visitas al sitio durante los meses de agosto y octubre del año 2018. En el mes de agosto se tuvo como objetivo el reconocimiento del área de estudio y el acercamiento a la población aledaña. En octubre, se efectuó el levantamiento de datos del sitio, mediante el llenado de fichas de las estructuras, registro fotográfico, sobrevuelo de dron en el área y la recopilación de la tradición oral del centro poblado Bellas Flores. Debemos aclarar que, por cuestiones logísticas, se abarcó el 80 \% del registro de las estructuras; de esta manera, los resultados alcanzados poseen dicha limitación.

\section{EL ÁREA DE ESTUDIO}

\subsection{El Alto Marañón}

Es toda el área definida por el curso del río Marañón, que comprende desde su naciente en el Nevado de Raura, tomando una dirección sudeste a noroeste, entre las Cadenas Occidental y Central de los Andes del Norte, hasta el pongo de Rentema; a partir de ahí toma una dirección hacia el noreste, entre las Cadenas Centro y Oriental de los Andes, hacia el pongo de Manseriche. Esta parte del río se caracteriza por presentar un cauce estrecho y profundo, con un declive muy acentuado (SENAMHI, 2011). Así mismo, está conformado por cerros de pendientes pronunciadas con vegetación muy espesa, sobre todo, arbustiva (Ibarra, 1999). La zona del Alto Marañón 
representa una de las últimas montañas antes de llegar a la selva (Mantha y Malca, 2016, p. 165), que ha servido de escenario a diversos grupos sociales que aprovecharon los diferentes pisos ecológicos que comprende.

\subsection{Sitio arqueológico Huata}

Huata está emplazada en la cúspide de un cerro del mismo nombre, a $3800 \mathrm{~m} \mathrm{s.} \mathrm{n.}$ m., flanqueado por los ríos Luyán y Aco, que desembocan en el río Marañón en su margen izquierda. Tiene vegetación densa, arbustiva y arbórea en determinados sectores del sitio, y está rodeada por pajonales de puna (ichu). Su composición florística está conformada por 64 especies, siendo 15,6\% endémicas, tales como Paronychia macbridei Chaudhri (Caryophyllaceae), Passiflora trifoliata Cav. (Passifloraceae), Puya llatensis L. B. Sm., P. stipitata L. B. Sm. (Bromeliaceae), entre otras (Montesinos-Tubée, 2016, p. 484).

Políticamente se ubica a $1.5 \mathrm{~km}$ al norte del Centro Poblado Menor Bellas Flores, en el distrito de Singa, en la provincia de Huamalíes del departamento de Huánuco. Con una orientación de este a oeste, ocupa aproximadamente 5 ha, con coordenadas de referencia 301287 E y $8965082 \mathrm{~N}$.

Por el norte, se ubican laderas aterrazadas que tienen mayor pendiente a medida que se desciende hasta el río Luyán. Por el sur, una gran cantidad de terrazas de cultivo que son utilizadas hasta la actualidad por los pobladores de Bellas Flores. Por el este, un gran abismo hace inexpugnable cualquier tipo de acceso. Finalmente, por el oeste, se asciende hacia el cerro Carhua, en cuya falda y cima se emplazan dos sitios arqueológicos: Costalperga y Carhua (figura 1).

\section{ANTECEDENTES}

\subsection{Cronología en el Alto Marañón}

El francés Bertrand Flornoy fue pionero en el estudio del valle de Tantamayo, así mismo, en realizar las primeras exploraciones arqueológicas en 1947; sin embargo, Louis Girault es quien inicia los trabajos de excavación en Piruro, entre los años 1968 y 1970, pero debido a su temprano deceso, los trabajos fueron secundados por Elisabeth Bonnier en la década del 80, quien a partir de un análisis estratigráfico establece secuencias ocupacionales desde el Período Precerámico (2500 a. C. - 1800 a. C.) hasta el Período Inicial (1800 a. C.-900 a. C.), con una interrupción de 1500 a 2000 años, para posteriormente ser ocupada durante el Intermedio Tardío (1000 d. C. 1470), Horizonte Tardío (1470 d. C.-1532 d. C.) y comienzos de la colonia (Bonnier y Rozenberg, 1987; Bonnier, Zegarra y Tello, 1985; Bonnier 1981).

Esta propuesta es afín al aporte de otra integrante del proyecto, Catherine Rozenberg, cuya tipología de cerámica, arroja 4 tipos. El Tipo A (Tantamayo Rojo Estampado): son vasijas de color anaranjado, rojo, beige o marrón; posiblemente comprende desde fines del Horizonte Medio o Intermedio Tardío. Tipo B (Tantamayo Marrón 


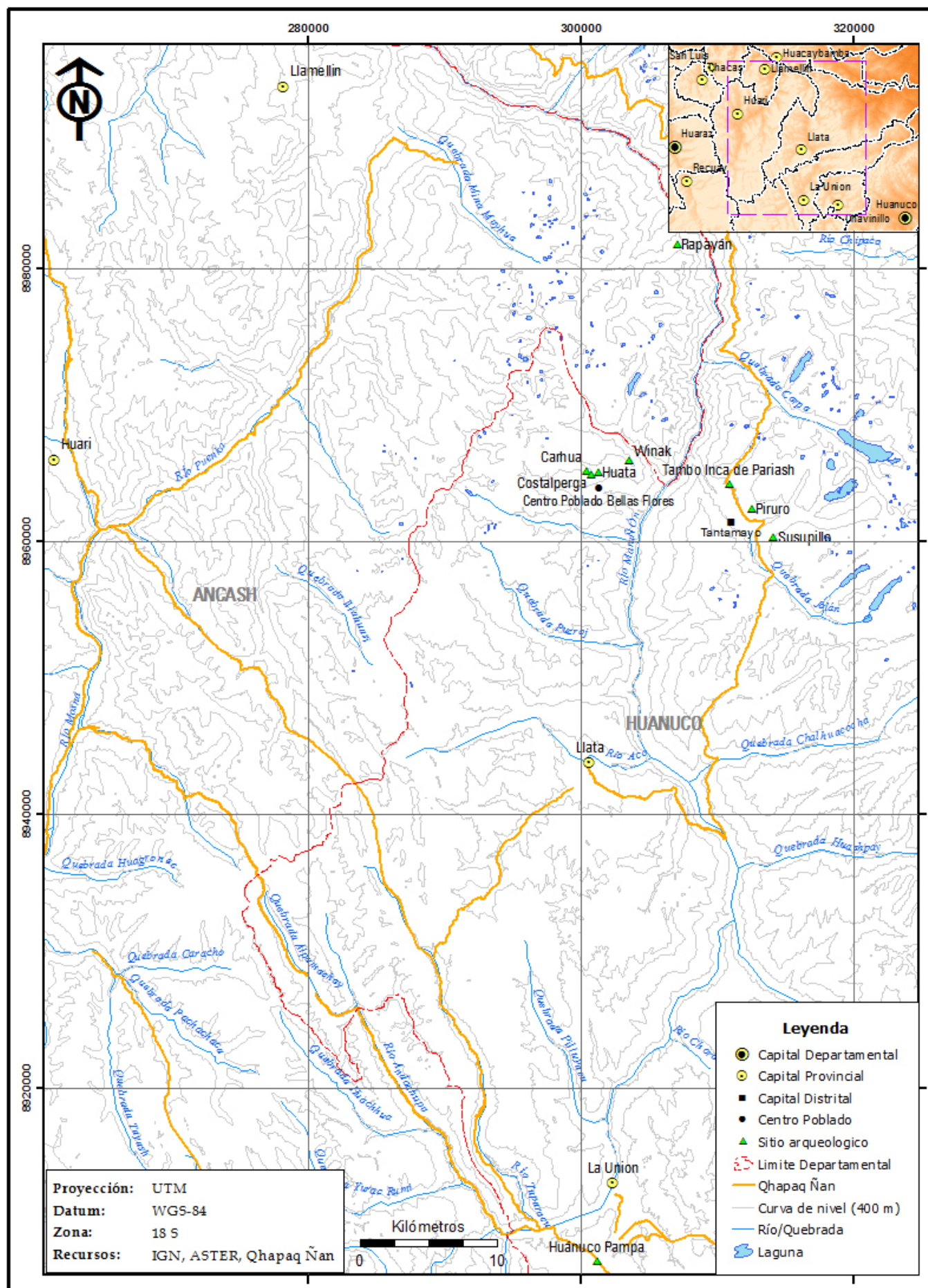

Figura 1. Mapa del área de estudio 
Micáceo): conformado por cuencos, jarras y tazas de color marrón, de superficie brillante producto de la inclusión de mica; se correlacionaría al Intermedio Tardío. Tipo C (Pariash): se trataría de un estilo local con influencia inca del Horizonte Tardío. Por último, el Tipo D (Piruro): compuesta por ollas cerradas y sin cuello, que corresponde a ocupaciones más tempranas de Piruro, es decir, al Período Inicial (1800 a. C. al 900 a. C.) y Horizonte Temprano (900 a. C. al 200 a. C.) (Bonnier, Howard, Kaplan y Rozenberg, 1983). Los resultados de ambos trabajos permiten sostener que los tipos de cerámica A y B están correlacionadas a la arquitectura de superficie de Piruro, correspondiente al período Intermedio Tardío; mientras que el tipo Pariash se relaciona a la ocupación inca en la zona.

En un área ubicada al norte de Tantamayo, Rapayán (Áncash), Alexis Mantha y Rafael Malca (2017), contrario a lo que sucede en Tantamayo, sugieren una ocupación continua desde el Período Inicial hasta el Horizonte Tardío y probablemente hasta la época colonial. Su propuesta de una ocupación desde el Horizonte Temprano hasta el Horizonte Medio se basa en la presencia de cerámica parecida al estilo Chavín y estilos similares a las de Recuay. En cuanto al Horizonte Medio, aún resulta más incierto debido a que no hay un estilo definido para ese período, razón por la cual faltan más estudios de tipología cerámica y fechados radiocarbónicos.

De otro lado, Luis Salcedo (2012) también aporta a la cronología del Alto Marañón, a partir de un análisis tipológico de la arquitectura, en especial de las chullpas, en la que propone dos fases de ocupación para lo que él denomina la tradición Wamallí. Durante la Fase Temprana (750 d. C. al 1150 d. C.) las chullpas son más elaboradas, presenta mampostería fina con enlucido y pintura, con alturas de 4 a $6 \mathrm{~m}$; mientras que, para la Fase Tardía (1150 d. C. al 1450 d. C.) las chullpas son menos elaboradas y más bajas, midiendo entre 3 y $4 \mathrm{~m}$. En ambas fases el patrón de asentamiento varía, en la primera ocupan las áreas bajas del cerro y en la segunda, ocupan las partes altas. Examinando lo anterior, cabe la posibilidad de que las diferencias formales de las chullpas, no necesariamente se deban a variaciones en el tiempo, sino se deban a estilos y técnicas de los numerosos grupos sociales que habitaron el área.

En relación con lo señalado, para el Alto Marañón se registran ocupaciones desde períodos tempranos hasta tardíos en algunos de los sitios investigados. Sin embargo, falta definir la cronología de otros asentamientos para tener un panorama más amplio de las distintas ocupaciones en el área.

\subsection{Arquitectura en el Alto Marañón}

Los grupos sociales que ocuparon el Alto Marañón han tenido como uno de sus elementos más notables la arquitectura, destacando entre ellas los edificios de varios niveles. Tal fue su vistosidad que atrajo tempranamente la atención de cronistas como Vásquez de Espinosa, quien en el año 1628, anotaron en sus registros la presencia de "torrecillas" que se mostraban imponentes sobre la cima de los cerros, 
sugiriendo su posible uso funerario (1628[1992]). Posteriormente, a mediados del siglo XIX, los viajeros como Mariano Rivero y el italiano Antonio Raimondi, también reportaron la presencia de enormes "castillos" o "torres"; el primero para el valle de Tantamayo y el segundo para la margen izquierda del río Marañón, en el distrito de Singa; adjudicándose para ambos casos, su función como fortines (Raimondi, 1901; Rivero y Tschudi, 1851).

Es recién a mediados del siglo XX e inicios del XXI que se ha abordado con mayor seriedad el estudio y registro de la arquitectura de los asentamientos en el Alto Marañón. Para la zona norte, que abarca parte de las provincias de Huamalíes, Huacaybamba y Huari, tenemos áreas como Tantamayo (Huánuco) y Rapayán (Áncash), ubicadas en ambas márgenes del Marañón, que son los que más atención han recibido. En el primer caso, los esfuerzos desplegados fueron dirigidos principalmente a la arquitectura de los períodos más tempranos de Piruro, así mismo, reportaron 81 sitios arqueológicos de todo el valle, identificando en ellas viviendas de forma rectangular, depósitos, edificios con posible función funeraria, corrales y terrazas de cultivo (Bonnier, 1981). El área Rapayán, ubicado más al norte, tras excavaciones y demás estudios realizados por Alexis Mantha, arroja que se trata de asentamientos conformados por viviendas de planta rectangular con divisiones internas, que, para su mejor estudio y comparación con otras zonas, se les ha denominado "tipo de casa Rapayán" (Mantha, 2015, p. 438). Entre otros tipos de arquitectura reportada figuran chullpas, depósitos, galerías y edificios de varios pisos, similares a las registradas en Tantamayo (Mantha y Malca, 2004).

En la zona sur del Alto Marañón, que corresponde a las provincias modernas de Dos de Mayo, Yarowilca y Lauricocha, se han identificado recintos de forma circular y en planta en D; asociados a estas, se hallan los edificios o "torres" que son de menor tamaño que las registradas en la zona norte como en Tantamayo y Rapayán (Onofre, 2012; Salcedo, 2012; Morris y Thompson, 1985; Morales, 1984). Estos en algunos casos presentan diseños singulares en su fachada principal, en forma de "+" o "T" en sitios como Garu, Quinaj, Chiquia y Ticra (Salcedo, 2012).

Por otro lado, la presencia inca en algunos asentamientos de la zona, se reflejó en la aparición de estructuras con características propias que difieren del patrón arquitectónico local. Tales son las grandes estructuras rectangulares asociadas a espacios abiertos, para unos casos claramente se tratan de Kallankas como en el sitio arqueológico Garu (Salcedo, 2012), mientras que en otros no se lo ha identificado como tal (Mantha, 2017). Otro elemento que denota esta filiación es la presencia de colcas, de planta cuadrangular o rectangular, que se emplazan alineadas unas tras otras como en el sitio arqueológico Garu (Salcedo, 2012). Situación similar ocurre con la llegada de los hispanos, que no pasó desapercibida en el Alto Marañón, notándose claramente en la arquitectura religiosa, iglesias o capillas, de planta rectangular con techo a dos aguas, ubicadas de forma aislada, pero cerca a 
algunos asentamientos y otras veces al interior de ellos como en Chiquia y Huánuco Pampa (Ordóñez y Castro, 2015; Salcedo, 2012).

Por tanto, observamos que existen notables diferencias en la arquitectura de la parte norte y sur del Alto Marañón, sobre todo en cuanto a los edificios de varios pisos o también llamados "torres". Para el primer caso presentan mayor altura, volumen y varios niveles; $y$, para el segundo, son de menor tamaño, de un solo nivel y, en algunos casos, presentan elementos ornamentales en forma de "+" o " $T$ ". Lo que sí es común en ambas zonas es que estos edificios o torres están emplazadas junto a la arquitectura doméstica, sin una clara separación espacial entre un tipo arquitectónico y otro. Tras la llegada de los incas y la posterior incursión hispana se distingue la aparición de elementos arquitectónicos foráneos que difieren claramente de las tradiciones locales.

\section{RESULTADOS}

\subsection{Cronología del sitio arqueológico Huata}

Una fuente etnohistórica temprana, haciendo referencia a la visita de Miguel de La Serna y Juan de Espinosa en 1549, indica el momento final de la ocupación de Huata. En ella se señala, que, al momento de la visita, Huata estuvo aún habitada por "veinte seis indios y diez y seis casas pobladas de indios viejos e viudas", y que se desempeñaron en diversas actividades tales como la agricultura, caza de venados, crianza de ganados y la extracción de oro en lavaderos. Seguidamente, cuando se les interrogó para saber con qué cosas servían al Inca, adujeron "E que el oro y plata que sacaban lo llevaban al inga, al cuzco y ha doquier que les era mandado" (Serna y Espinoza, 2004 [1549], p. 152, 154). Como se describe, los pobladores primero sirvieron de diversos productos al Inca y, tiempo después, recibieron la visita de los hispanos. A partir de ello, podemos sostener con cierto grado de confianza que Huata fue ocupada durante el Horizonte Tardío e inicios de la Colonia. Incluso existen evidencias arquitectónicas que respaldan su última ocupación, debido a que se ha identificado una arquitectura de factura colonial, la cual se detalla más adelante.

Siguiendo esta premisa, se ha realizado un análisis comparativo entre Huata y los sitios con afiliación tardía de la zona, llegando a la conclusión que existen semejanzas arquitectónicas con el sitio de Rapayán (departamento de Áncash). Ambas comparten características formales que no solo estarían sugiriendo su contemporaneidad, sino también su posible pertenencia a un mismo grupo cultural.

Otro indicador cronológico, son los edificios de varios pisos, que están presentes en Rapayán como en el valle de Tantamayo y que comparten técnicas constructivas, diseño y monumentalidad similares a los de Huata. Los resultados de las excavaciones de Mantha y Malca (2017) en Rapayán arrojan que dichos edificios se habrían construido durante el Intermedio Tardío (1000 d. C. - 1470) y siguieron ocupándose 
hasta el Horizonte Tardío. Las estructuras de superficie de Piruro en Tantamayo, incluso cuentan con fechado radiocarbónico que también los sitúa en los mismos períodos tardíos (Bonnier, 1981). En ese sentido, haciendo un análisis comparativo de la arquitectura entre estos sitios y Huata, creemos que posiblemente se habrían construido durante el mismo período, es decir en el Intermedio Tardío (1000 d. C. 1470 d. C.) (ver Figura 2).
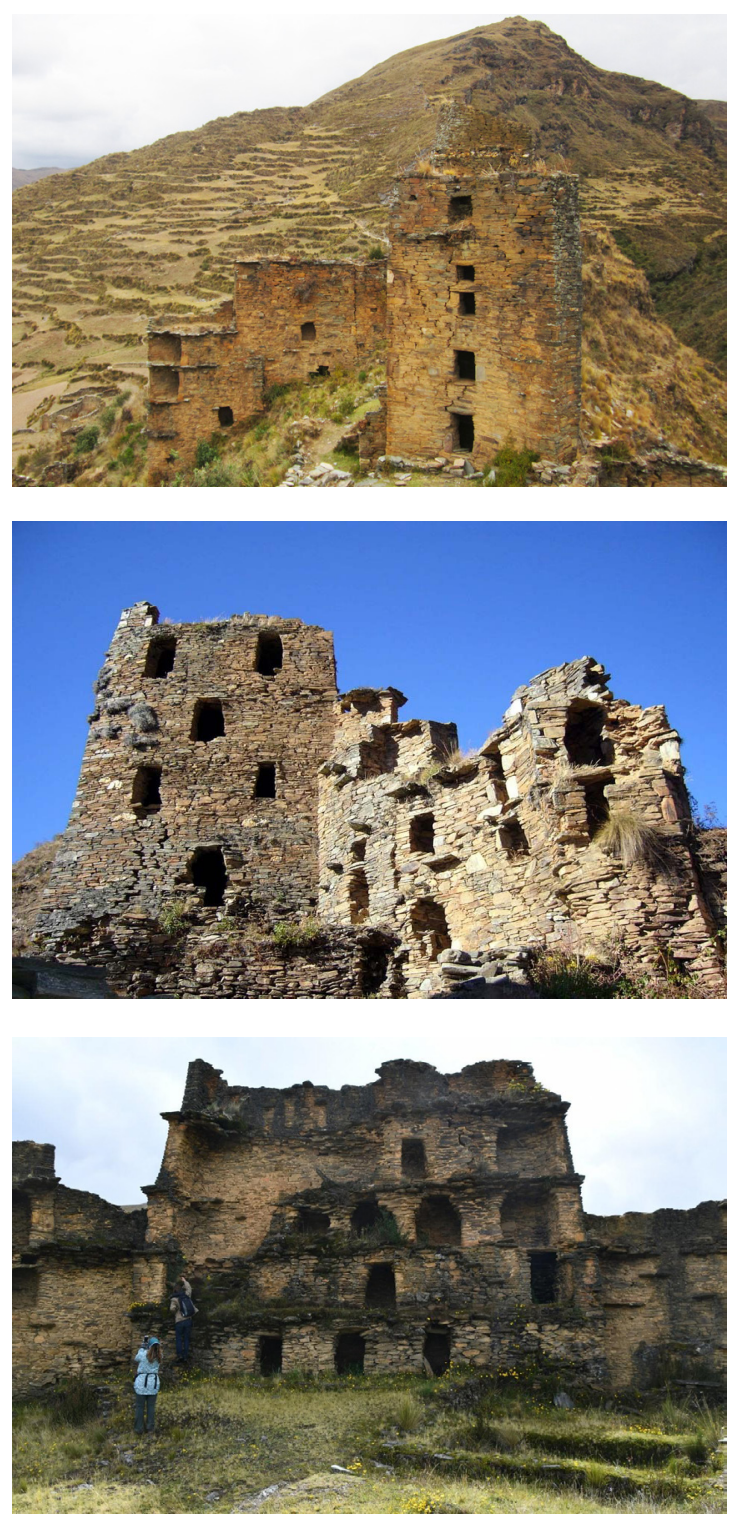

a. Sitio arqueológico Huata.

b. Sitio arqueológico Rapayán (Imagen tomada de Mantha, 2006, p. 47).

c. Sitio arqueológico Piruro (Tantamayo) (Imagen tomada de Ingham, 2019, p. 147).

Figura 2. Nótese como los edificios comparten un diseño, técnica y monumentalidad similar. Investigaciones en Rapayán y Piruro lo ubican cronológicamente para el período Intermedio Tardío. 
Finalmente, los patrones de asentamiento también pueden sugerir temporalidad. La mayoría de los sitios del Alto Marañón se emplazan en la cima de los cerros, con acceso a pastizales en las partes altas y terrazas de cultivo en las zonas bajas. Dicho patrón coincide con lo reportado para los sitios tardíos del área (Salcedo, 2012; Mantha y Malca, 2004, Bonnier, 1981; Pinilla y García, 1981) y en zonas vecinas como Áncash (Herrera, Amaya y Aguilar, 2011).

A partir de los datos expuestos se desprende entonces que, Huata habría sido un asentamiento cuya ocupación se remonta al período Intermedio Tardío hasta inicios de la colonia, probablemente hasta 1572, tiempo en que se dan las reducciones indígenas y se abandonan las antiguas llactas. Los ayllus de la zona fueron concentrados en la nueva reducción de San Pedro y San Pablo de Singa (Espinoza, 2004). Décadas más tarde, cuando el arzobispo Toribio de Mogrovejo (Angulo, 1921 [1593]) visita los pueblos de la zona, no llega a Huata, confirmando con ello, que este y otros asentamientos aledaños habían sido probablemente deshabitados.

Siendo este el escenario, aún quedan dudas en cuanto a la ocupación de Huata antes del Intermedio Tardío, tomando en cuenta la larga ocupación de asentamientos cercanos, como Piruro y Rapayán, pensamos que el sitio en estudio podría tener una ocupación más antigua. Sobre esto, la tipología arquitectónica realizada por Salcedo (2012) sugiere que Huata podría haber sido ocupado desde fines del Horizonte Medio, sin embargo, al no contar con más información y sin el respaldo de una excavación arqueológica, aún sigue siendo una débil propuesta.

Cuadro 1: Propuesta cronológica del sitio arqueológico Huata.

\begin{tabular}{|l|l|l|l|}
\hline PERIODO & $\begin{array}{l}\text { CRONOLOGÍA } \\
\text { RELATIVA }\end{array}$ & OCUPACIONES & INDICADORES \\
\hline $\begin{array}{l}\text { Intermedio } \\
\text { Tardío }\end{array}$ & 1000 a 1470 d. C. & Ocupación local & $\begin{array}{l}\text { - Arquitectura local. } \\
\text { - Patrón de asentamiento. }\end{array}$ \\
\hline $\begin{array}{l}\text { Horizonte } \\
\text { Tardío }\end{array}$ & 1470 a 1532 d. C. & $\begin{array}{l}\text { Ocupación local con } \\
\text { influencia inca. }\end{array}$ & $\begin{array}{l}\text { - Estructuras rectangulares } \\
\text { con influencia inca (i?). } \\
\text { - Evidencia etnohistórica de } \\
\text { la influencia inca en la zona. }\end{array}$ \\
\hline Colonia & 1532 a 1572 d. C. & (Encomiendas) & $\begin{array}{l}\text { - Arquitectura colonial } \\
\text { (Iglesia). } \\
\text { - Documento etnohistórico } \\
\text { (Visita de 1549 por Miguel } \\
\text { de La Serna y Juan de Espi- } \\
\text { nosa). }\end{array}$ \\
\cline { 2 - 4 } & 1572 d. C. & Abandono del sitio. & $\begin{array}{l}\text { - Reducción de San Pedro y } \\
\text { San Pablo de Singa. }\end{array}$ \\
\hline
\end{tabular}




\subsection{Arquitectura del sitio arqueológico Huata}

\subsubsection{Sectorización}

Al emplazarse en la cresta de un cerro el asentamiento se adapta a la irregular geomorfología del terreno, área en la que se construyeron terrazas para nivelar y crear espacios, aprovechando los afloramientos rocosos y las zonas de abismo como baluarte natural. Para realizar la sectorización se han considerado las características topográficas y la organización arquitectónica que posee. En ese sentido el sitio está compuesto por 3 sectores: A, B y C.

Sector A. Ubicado hacia el extremo oeste, está conformado por estructuras de forma ovalada y circular, que, por lo general, presentan nichos y cámaras de diferentes tamaños en sus paramentos internos. Se encuentran aglutinados a lo largo de la cresta del cerro y ocasionalmente cuentan con pequeños espacios abiertos asociados. Por otro lado, en la sección central se yerguen 6 edificaciones de varios pisos, de planta rectangular, tres de ellos adosados, pero manteniendo accesos independientes. Están asociados a espacios abiertos de regulares proporciones.

Llama la atención la presencia de 2 estructuras de planta rectangular de un solo nivel, una de ellas con división interna, cuyas características difieren con el patrón arquitectónico local y su funcionalidad es desconocida, y está ubicada en una terraza inferior, asociada a un espacio abierto de grandes dimensiones; mientras que, la otra, se ubica en la parte más elevada junto a los recintos ovalados. Adicionalmente, existen otros tipos de estructuras de planta rectangular con división interna, pero de menores dimensiones y de carácter doméstico denominadas "tipo de casa Rapayán" (Mantha, 2015: 447), encontrando 3 aproximadamente al inicio de este sector.

Hacia el extremo este del sector se ha identificado un conjunto de pequeñas estructuras (chullpas) dispuestas alrededor de un espacio abierto, sobre afloramientos rocosos previamente nivelados para crear un área plana. Estructuras como estas también pudieron ser identificadas junto a algunos de los recintos ovalados mencionados líneas atrás. Al finalizar este sector, al extremo este, se han observado restos de lo que podría ser una muralla.

Casi todas las estructuras están construidas con piedras angulosas pequeñas y medianas, unidas mediante argamasa, con una apariencia tosca e irregular, a excepción de los edificios de varios pisos que presentan un mayor esmero en su construcción. Por último, el estado de conservación del sector es regular, debido a que algunas estructuras se encuentran muy destruidas y los edificios de varios niveles presentan rajaduras que ponen en peligro su integridad.

Sector B. Ubicado hacia el extremo este del sitio, delimita, dando inicio a este sector, una muralla con cámaras funerarias donde aún se puede apreciar restos óseos humanos. En general se repite la misma configuración arquitectónica y un manejo 
espacial similar al sector A, es decir, está constituido por estructuras ovaladas y circulares, un edificio de varios pisos en la parte central y un conjunto de chullpas asociadas a un pequeño espacio abierto al final del sector. Nuevamente se hallan las estructuras "tipo de casa Rapayán", pero en mayor proporción respecto al sector A, identificándose alrededor de cinco. Dichas construcciones se caracterizan por tener un mejor acabado en los paramentos y nichos, mediante el uso de piedras talladas y planas, dándole así un aspecto más fino. Pese a estas características es el sector menos conservado de todo el asentamiento.

Sector C. Está conformado por dos estructuras aisladas de planta rectangular con esquinas rectas, su técnica constructiva es más tosca y posee elementos arquitectónicos diferentes respecto a las demás estructuras de todo el asentamiento.

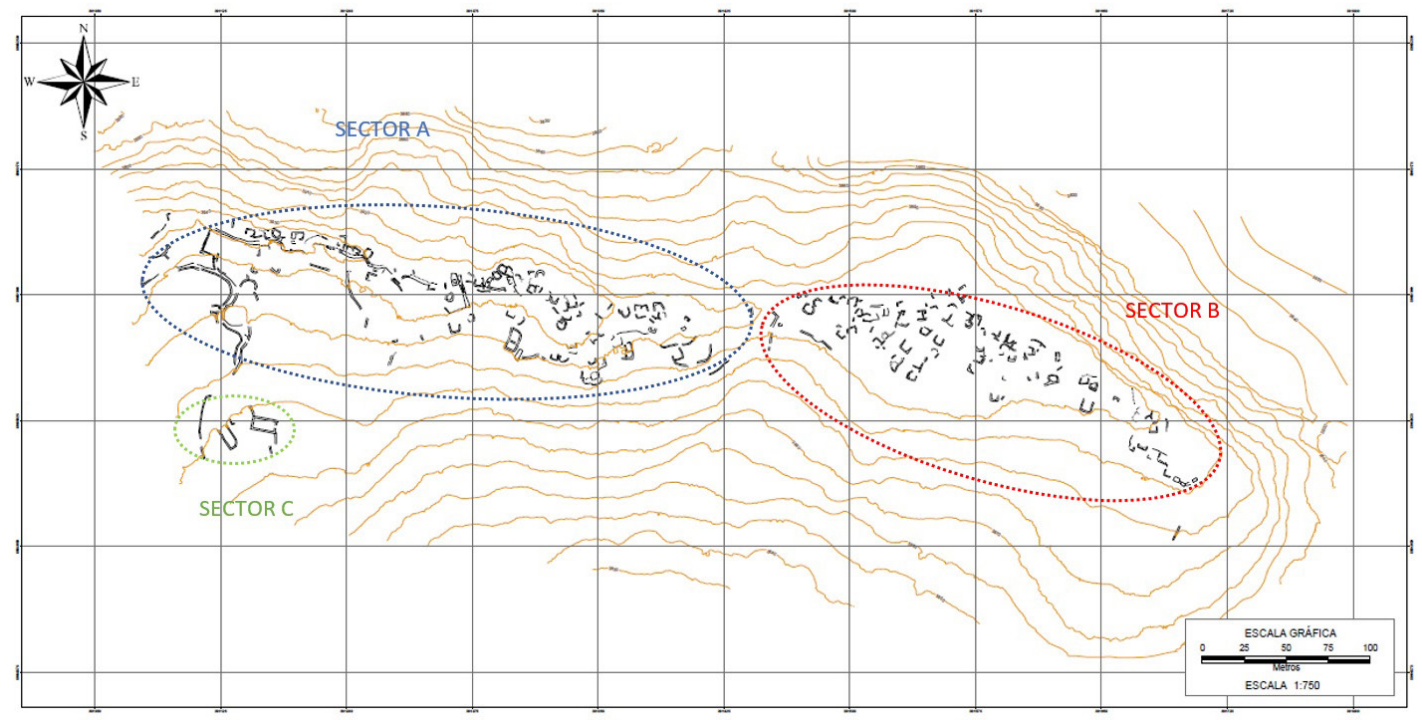

Figura 3. Plano topográfico y arquitectónico del sitio arqueológico Huata y sus 3 sectores.

\subsubsection{Tipología arquitectónica}

\section{Estructuras domésticas}

Este tipo de arquitectura es la que más predomina en el sitio arqueológico Huata, donde se halla 93 aproximadamente, distribuidos en los sectores A y B, cuyos emplazamientos son similares en ambos casos, pues se ubican en tres niveles aterrazados hacia el sur, ya que hacia el norte se ve limitada por una pendiente pronunciada. Las estructuras se disponen de forma continua y aglutinada, adecuándose al relieve natural. Tienen planta de forma circular, ovalada, predominando las de forma irre- 
gular y, por lo general, los muros externos son rectos, con accesos independientes que en su mayoría se orientan al sur y al oeste. El promedio de sus dimensiones es $2.20 \mathrm{~m}$ de alto, $4.40 \mathrm{~m}$ de largo y $3.50 \mathrm{~m}$ de ancho.

Por las características de emplazamiento, forma y técnica constructiva de este tipo arquitectónico, podemos denominarlos como "viviendas", pues las investigaciones en sitios tardíos en el Alto Marañón (Mantha y Malca, 2017, 2016, 2004; Mantha, 2015, 2013, 2009 y 2013; Amat, 2013; Onofre, 2012; Salcedo, 2012, 2010; Ibarra, 1999; Bonnier y Rozenberg, 1987; Morris y Thompson, 1985; Ravines, 1984; Morales, 1984; Bonnier, 1984; Pinilla y García, 1981; Flornoy, 1957) respaldan esta idea, ya que poseen formas arquitectónicas similares y afines a una función doméstica. Además, intervenciones específicas en este tipo de arquitectura han permitido ver su asociación a estratos de actividades domésticas (Mantha, 2015; Onofre, 2012; Salcedo, 2012, 2010; Morales, 1984). Por ejemplo, en el sitio arqueológico Rapayán, Alexis Mantha (2015) realiza excavaciones al interior de estas estructuras y registra mazorcas carbonizadas de maíz, huesos de llama y de cuy, una gran cantidad de fragmentos cerámicos con restos de hollín, morteros, piedras de moler y otras herramientas de uso doméstico al nivel del suelo, pertenecientes al periodo Intermedio Tardío.

$\mathrm{Al}$ interior de las viviendas se hallan cámaras, de una sola pieza, en la parte superior de las paredes, a modo de repisas, que varían en sus dimensiones, algunas incluso alcanzan más de $1 \mathrm{~m}$ de altura (ver figura 4). Externamente, otras como las identificadas en la parte baja del sector A, poseen hastiales, elementos arquitectónicos inusuales en la mayoría de las estructuras registradas.

La mayoría de las viviendas se componen de un espacio. Sin embargo, existen viviendas de doble espacio (ver figura 5), que cuentan con $2 \mathrm{~m}$ de alto, $4.70 \mathrm{~m}$ de largo
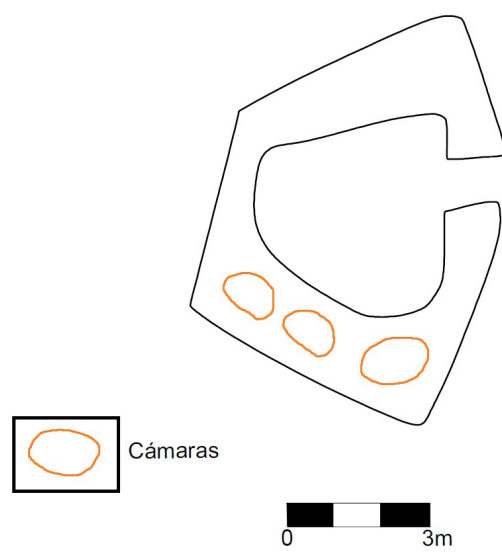

Figura 4. Vivienda representativa de Huata de un solo espacio (Sector A).

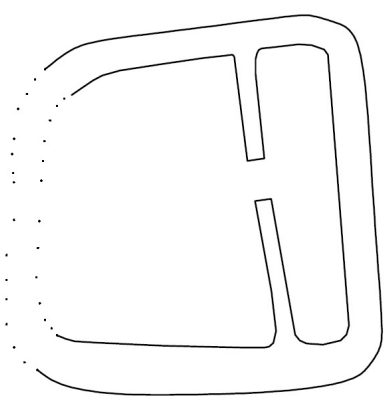

Proyección

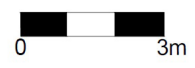

Figura 5. Vivienda "tipo Rapayán" de doble espacio (Sector B). 
y $4 \mathrm{~m}$ de ancho en promedio, siendo los más recurrentes en el sector B; que poseen un mayor esmero en su mampostería y presentan un mejor acabado en los muros, nichos y accesos. Este tipo de viviendas han sido denominadas como "tipo de casa Rapayán" y han sido reportadas en un sitio arqueológico del mismo nombre, ubicado al noreste de Huata (Mantha, 2015).

Las viviendas en Huata probablemente no solo cumplieron una función doméstica como tal, sino también funeraria, pues al interior se han encontrado una variedad nichos $u$ hornacinas de formas cuadradas o rectangulares. Los nichos, generalmente se ubican en la parte media de la pared, pero otros están a la altura del piso, sus dimensiones varían de $0.72 \mathrm{~m}$ (alto) y $0.61 \mathrm{~m}$ (ancho) a $0.12 \mathrm{~m}$ (alto) y $0.24 \mathrm{~m}$ (ancho). Algunos posiblemente fueron lugar de depósito mortuorio perteneciente a parientes de los residentes. Esta última idea ha sido señalada por Alexis Mantha (2015), quien encuentra una situación similar en Rapayán, donde halla restos óseos de humanos en los nichos de las viviendas y, que, al ser complementadas con datos etnográficos, como entrevistas a los pobladores de la zona, indican que vieron restos óseos humanos al interior de estas estructuras. No obstante, tampoco puede descartarse el uso de estos nichos como depósitos.

Las viviendas están ubicadas en las terrazas construidas con muros de contención, donde trataron de aprovechar el más mínimo espacio disponible. Los ejes de los accesos de las estructuras domésticas no configuran espacios abiertos compartidos ni en el sector A ni en el sector B.

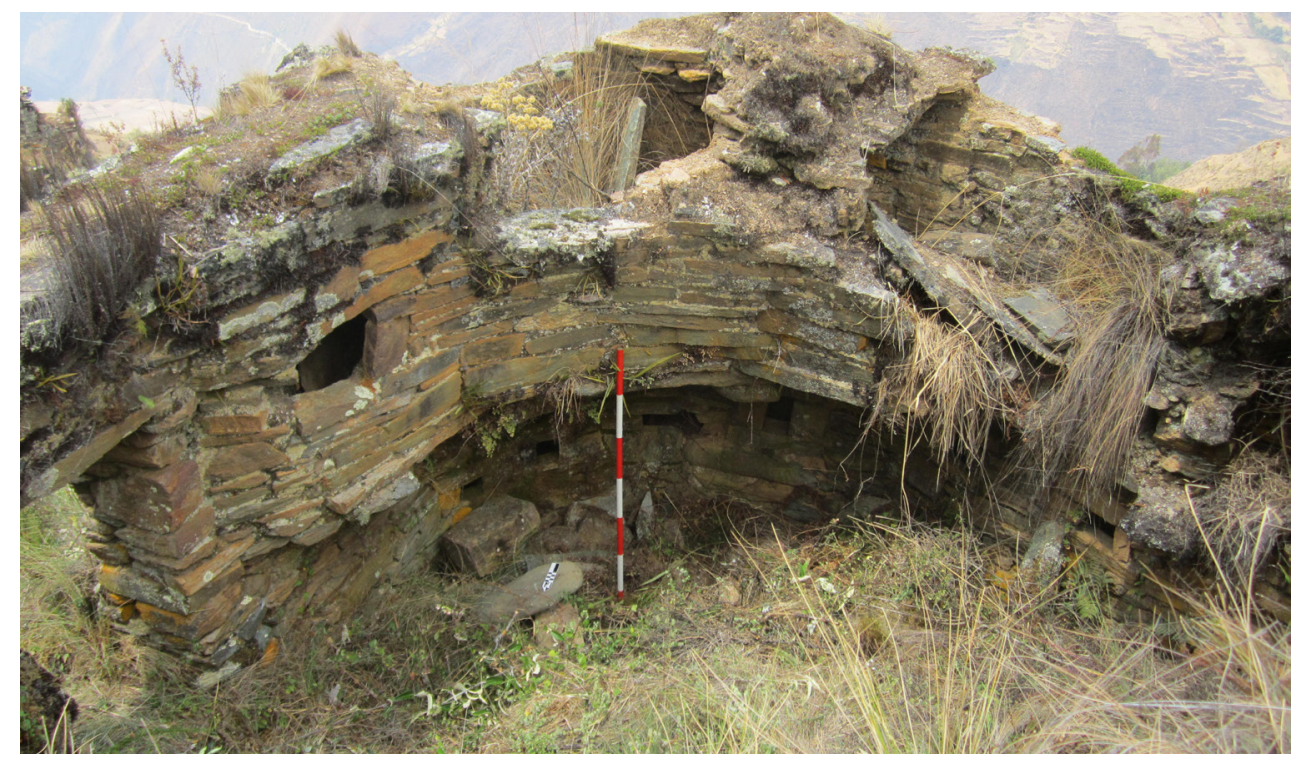

Figura 6: Detalle del interior de una vivienda representativa de Huata, de planta ovalada, con nicho y cámaras (Sector A). 


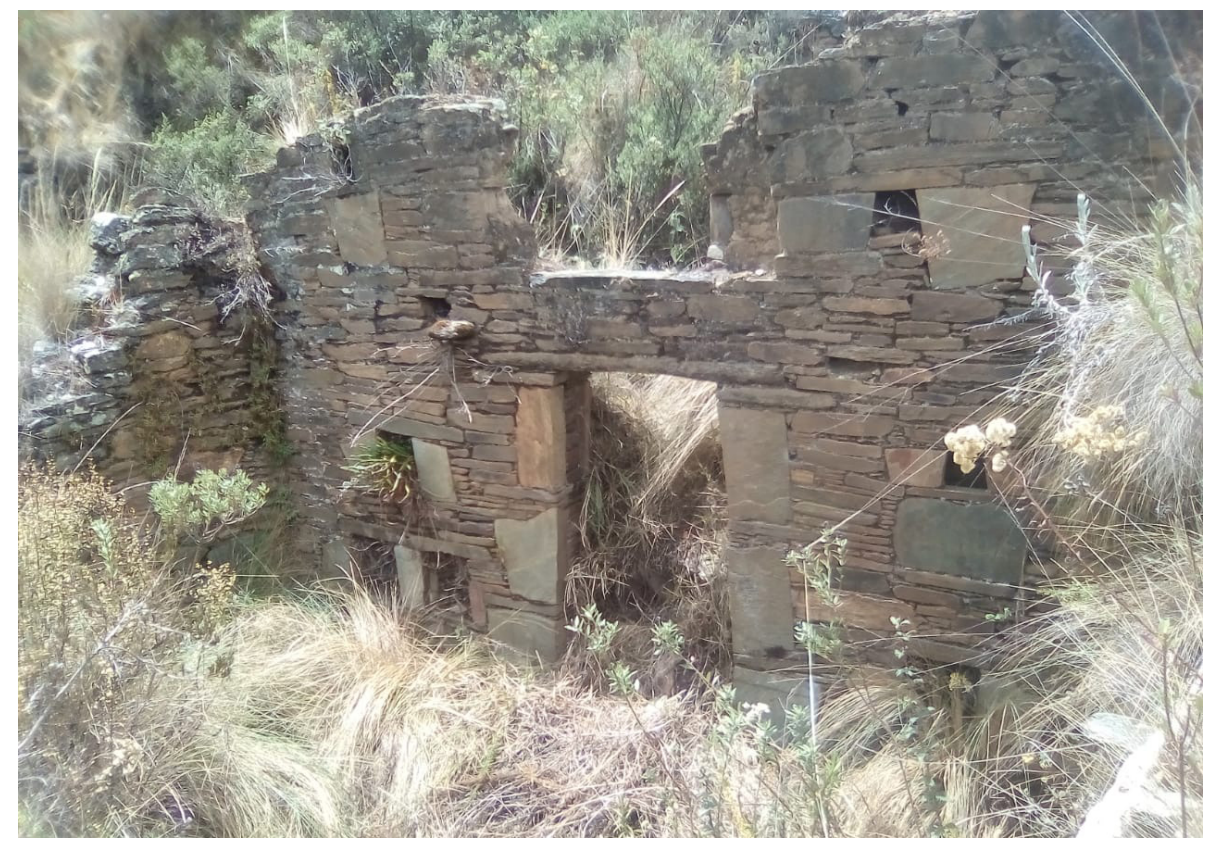

Figura 7: Muro que divide en dos espacios la vivienda "Tipo Rapayán", de planta rectangular (Sector B). Nótese la técnica constructiva más fina y el uso del lado plano de las piedras para darle un acabado estético al vano de acceso y a los nichos.

\section{Estructuras funerarias}

Tipo A: Edificios de varios pisos. Se registraron siete edificaciones de varios pisos distribuidos en los sectores A y B de Huata. En el sector A se han identificado seis, donde cinco de ellas están agrupadas en una zona más elevada adecuándose a la topografía en declive (ver figura 8), y el último se halla en una terraza inferior. Los edificios varían de tres a cinco niveles, midiendo el de mayor altura $9.15 \mathrm{~m}$ de alto y $5.65 \mathrm{~m}$ de ancho (ver figura 9); cada nivel termina con un techo que está conformado por enormes lajas que cruzan de un lado a otro, sobre el cual se han construido los siguientes niveles. Su forma externa es rectangular, pero internamente rematan en muros redondeados hacia las esquinas dándole mayor solidez a la estructura. Un grupo de estos edificios, conocido como "Matacastillo" está constituido por tres edificios adosados, con accesos independientes y voladizos en sus paredes externas e internas que permiten acceder a los niveles superiores. La que se ubica más hacia el sur, tiene tres niveles, dos de los cuales terminan como balcones que apuntan directamente hacia el único espacio abierto del sector. Todos ellos se emplazan contiguos a recintos de carácter habitacional.

En el sector B, solo hemos identificado uno de estos edificios, se encuentra semidestruido, pero con las características formales semejantes a las del sector A. Tam- 
bién está rodeada de viviendas y no se pudo determinar su asociación a espacios abiertos. En ambos casos estos edificios poseen vanos orientados al este y oeste, y se emplazan en la parte central de sus respectivos sectores.

Las características que los distinguen de otras edificaciones del lugar se evidencian en variables como: su emplazamiento, por estar ubicadas en la parte nuclear de un asentamiento y su asociación a espacios abiertos, en especial a uno de 17 por $22 \mathrm{~m}$, es un indicio de su importancia y su diferenciación respecto a los recintos habitacionales, los cuales se encuentran aglomerados. Por la técnica constructiva, poseen características formales singulares, como una planta rectangular y un mayor esmero, que le dan solidez y mejor acabado. Incluso, una de las estructuras presenta una decoración de cuarzo blanco ordenado en hilera, como coronando la cabecera del edificio. Ornamentación similar se ha reportado en sitios como Susupillo II y Piruro II (Pinilla y García, 1981). Y, finalmente dos variables propuestas por Moore (1996) escala y visibilidad, referido a la monumentalidad de este tipo de arquitectura, que en primera instancia nos da cuenta de su importancia social, ya sea de carácter público o ceremonial/ritual, debido a que para su construcción se ha necesitado una mayor organización del trabajo y de los recursos disponibles. Su gran visibilidad destaca a kilómetros de distancia, debido a que uno de los edificios sobrepasa los $9 \mathrm{~m}$ de alto.

Estas singularidades en sus características formales nos sugieren una función diferenciada respecto a los recintos habitacionales. ¿Pero qué nos dice la literatura arqueológica sobre estas estructuras? En los sitios de la cuenca del Alto Marañón, se han reportado edificaciones similares de varios pisos que han sido comúnmente denominados "castillos" por los pobladores locales. Para algunos se trataría de residencia de élite y de carácter público (Flornoy, 1957; Amat, 2013). Bonnier parece ser más clara y señala que se trataría de edificios funerarios (1981:53). Ibarra (1999) nos habla de mausoleos, cuyo indicador es la presencia de restos óseos. Pero los que mejor aclaran el tema son Mantha y Malca (2004), quienes siguiendo la idea de Bonnier e Ibarra, plantean que son edificios funerarios o inmensas chullpas donde colocaban los malquis de los ancestros fundadores. Finalmente, Salcedo (2012: 19) también señala que son chullpas que sirvieron para exponer a sus ancestros en los distintos nichos distribuidos por niveles. Estas propuestas se ven reforzadas por el testimonio del cronista Vázquez de Espinosa, quien señaló lo siguiente:

"... y a una legua hay muchos pueblos despoblados de los antiguos, y en ellos y en aquellos cerros muchas sepulturas de ellos a modo de torrecillas con las puertas al Oriente, y en cada torrecilla en lo alto y bajo muchos indios muertos sentados, enteros e incorporados, por ser aquel sitio siempre frío y de vientos sutiles, que con haber desde el tiempo de su gentilidad están de la suerte referida, parece que ayer se pusieron en aquellos sepulcros, que por haberlos visto lo escribo". (1628[1948], p. 453). 
En el año 2018, como parte del trabajo de campo, hemos tenido la oportunidad de conversar con los adultos mayores de la zona, quienes manifestaban que, de jóvenes hallaban abundantes huesos al pie de dichos edificios. En este caso, no sería aventurado pensar que los malquis expuestos en los diferentes niveles fueron desmembrados y arrojados a través de las ventanas por personas inescrupulosas en las últimas décadas o, en su defecto, fue un proceso que pudo haber empezado con los curas españoles que se establecieron tempranamente en el sitio.

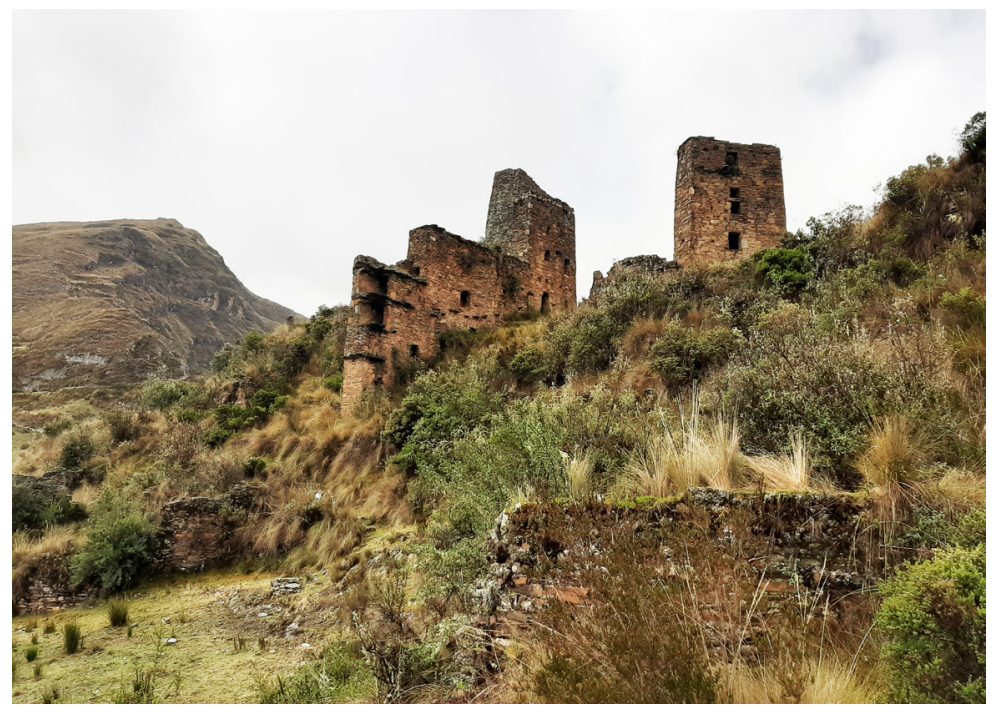

Figura 8. Edificios de varios pisos asociados a un espacio abierto ubicado en la parte baja.

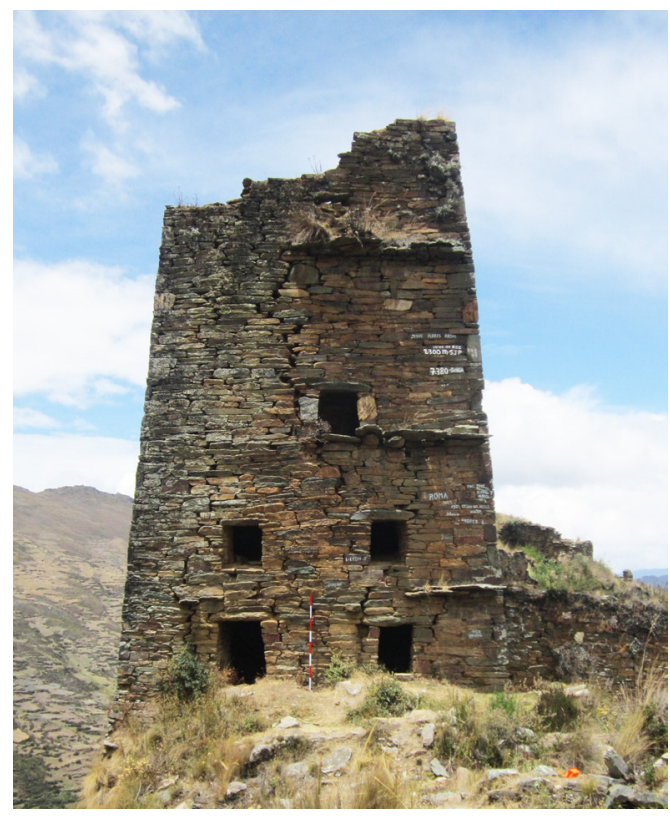

Figura 9. Detalle del edificio más alto del sitio (Sector A). 
Tipo B: Chullpas. Se identificó 29 de estas construcciones funerarias en los sectores A y B, son de menor tamaño, alcanzan $1.10 \mathrm{~m}$ de alto, $1.90 \mathrm{~m}$ de largo y $1.40 \mathrm{~m}$ de ancho en promedio, de planta rectangular con acceso central. Sus muros están hechos de piedra y argamasa, que sostienen un techo a base de grandes lajas de piedra. Poseen uno o dos niveles en cuyo interior, en contados casos, aún pueden observarse restos humanos. En el sector A, se los ha identificado asociado a algunas viviendas, sin embargo, hay una gran concentración de ellas hacia su extremo este, dispuestas alrededor de un pequeño espacio abierto y en las terrazas inferiores. Esta organización de las chullpas a un extremo del asentamiento se repite en el sector B. (figura 10).

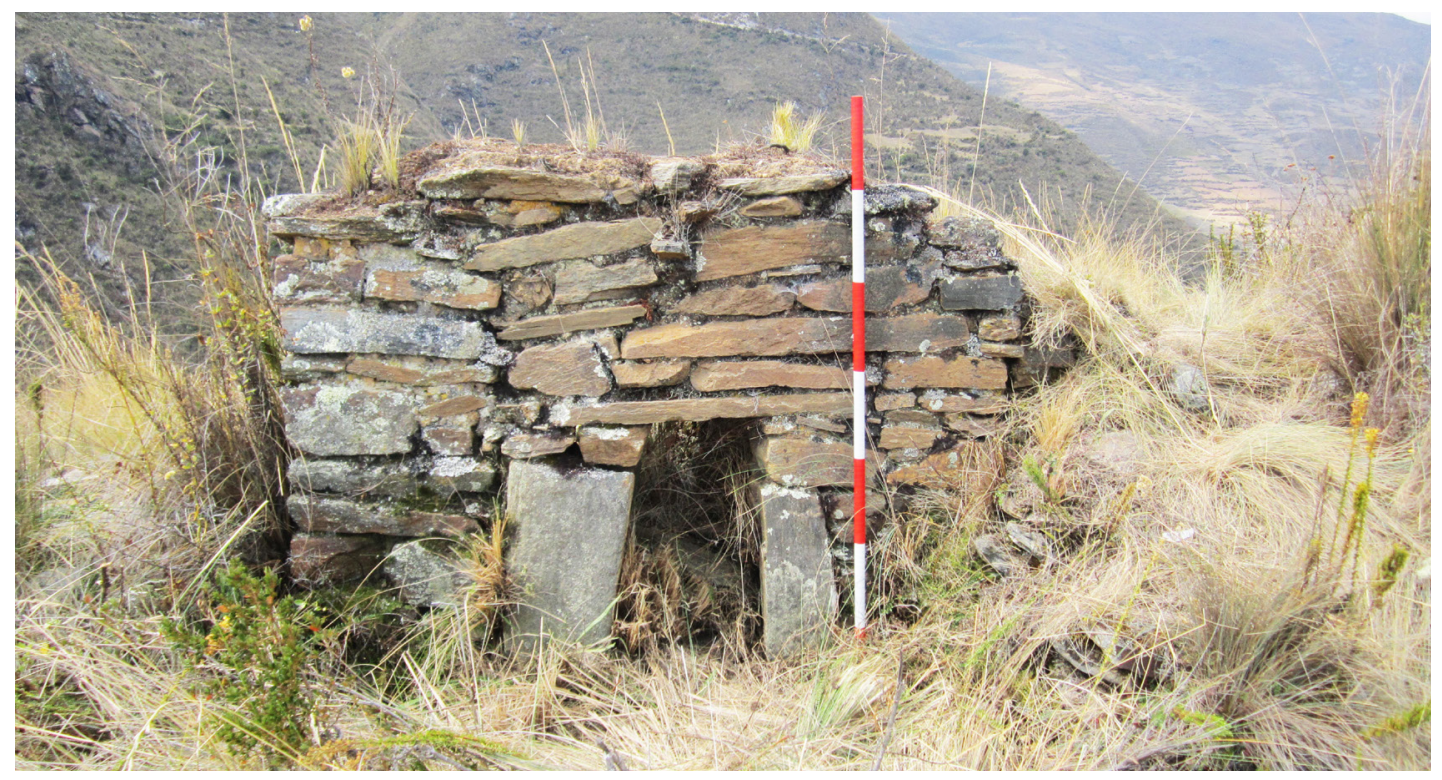

Figura 10. Chullpa típica de Huata.

Tipo C: Machay. Se trata de entierros en abrigos rocosos de difícil acceso, ubicado en la ladera norte del asentamiento y asociada a terrazas agrícolas. En el año 1998, un poblador de Bellas Flores, el señor Jacinto Espinoza Gaona halló un individuo momificado, siendo preservado desde aquella fecha en su propiedad. Por lo tanto, se trata del único resto humano recuperado de un machay asociado al sitio arqueológico, por ello, y para fines de esta investigación se le efectuó un análisis macroscópico durante nuestra segunda fase de estudio.

Como resultado se determinó que estos restos humanos probablemente corresponden a un individuo adulto de sexo femenino (Buikstra y Ubelaker, 1994) entre 20 a 30 años de edad (Krenzer 2006), la cual se encontraba en una posición anatómica 
flexionada y con los brazos orientados hacia la región abdominal; identificando además una notoria remodelación craneal de tipo tabular oblicua (Weiss, 1961).

A partir de lo expuesto, la existencia de los edificios funerarios de varios pisos y las otras dos formas de sepulcros, chullpas y machay, de características más modestas, sugieren que los cuerpos de los individuos de mayor estatus o linajes predominantes habrían ocupado los espacios mejor construidos, monumentales y bien ubicados para ser exhibidos en determinadas festividades rituales ante toda la comunidad. En los espacios abiertos asociados se habrían llevado a cabo rituales periódicos en honor a esos ancestros, entablando una suerte de "diálogo" entre los vivos y los muertos. Este tema ha sido bien abordado para la zona centro-sur de los Andes, donde incluso se habla de un "fenómeno chullpario" que terminan funcionando como lugares del culto (huacas) (Duchesne y Chacama, 2012; Kesseli y Parssinen, 2005). Todos los datos hasta aquí vertidos apuntan hacia el carácter funerario de dichas edificaciones de varios niveles, con pequeños espacios en su interior donde probablemente se colocaban a los malquis de los ancestros más insignes.

\section{Estructuras rectangulares}

Las viviendas del asentamiento son de planta ovalada o circulares, solo algunas de las viviendas conocidas como "tipo de casa Rapayán" y los edificios funerarios de varios pisos tienen una planta rectangular de menores dimensiones. Por ello, llama la atención la presencia de tres estructuras rectangulares de un solo nivel, donde una de ellas, la más grande mide $12.41 \mathrm{~m}$ de largo y $6.06 \mathrm{~m}$ de ancho (ver Figura 11), que rompe con el patrón arquitectónico del sitio. Dos de ellas se ubican en la parte central del sector A, uno en la parte baja, con división interna y asociado al único espacio abierto; y, el otro, en la parte más elevada del sector, donde aparentemente se habría alterado una estructura anterior para darle la forma rectangular. Otra de estas estructuras se ubica hacia el extremo este del sector B, en la parte baja, asociada a un espacio abierto.

En el valle del Huallaga existen reportes que dan cuenta de estructuras rectangulares en asentamientos como Ichu, donde se encontró dos estructuras rectangulares subdivididas en dos o tres cuartos, con mejores acabados que los demás recintos y con presencia de cerámica inca policromada en uno de ellos (Hyslop, 2016). Situación similar sucede en sitios cercanos como Akush y Suncho, donde aparecen estructuras de plantas rectangulares, diferentes al patrón local, pero similares en cuanto al acabado de su mampostería, que, curiosamente, se emplazan al centro de los asentamientos, o como en el caso de Suncho, cerca de las estructuras de mayor tamaño (Grosboll, 1993). Otros ejemplos, son de sitios como Hatunmarca y Marca en el valle del Mantaro, antes de la presencia inca sus edificaciones eran circulares, posteriormente, a la llegada de los cusqueños aparecen docenas de recintos 
rectangulares, aparentemente habitados por la élite local. Estos habrían adoptado la forma rectangular como símbolo de su nueva relación con el Imperio inca. "Los edificios rectangulares probablemente aumentaron el prestigio de sus habitantes, quienes demostraron su nueva afiliación política mediante la forma de sus hogares" (Hyslop, 2016).

Lo señalado resulta interesante debido a que una de las estructuras rectangulares en Huata, se encuentra asociado a un espacio abierto (¿plaza?) y está ubicada en lo que consideramos es el área central del sector A. La otra estructura, en el sector B, no se ubica en la parte central del asentamiento, pero está asociada a un gran espacio abierto. Estas ubicaciones privilegiadas, en un área central y asociada a posibles plazas, sugieren que podría tratarse de viviendas de jefes locales o personajes de la élite, que buscaron diferenciarse asimilando un patrón distinto y de ese modo resaltar su estatus dentro de la comunidad. Futuras excavaciones podrían ayudar a despejar el tema, ya que si se halla un acceso diferenciado a bienes y recursos respecto a otras estructuras, se corroboraría que este grupo ha adoptado patrones foráneos y accedió a bienes de prestigio. Sin embargo, tampoco puede descartarse su origen colonial, debido a que, en las terrazas agrícolas de los niveles bajos, se han identificado cerca de 9 estructuras rectangulares dispersas, siendo una de ellas de factura hispana.

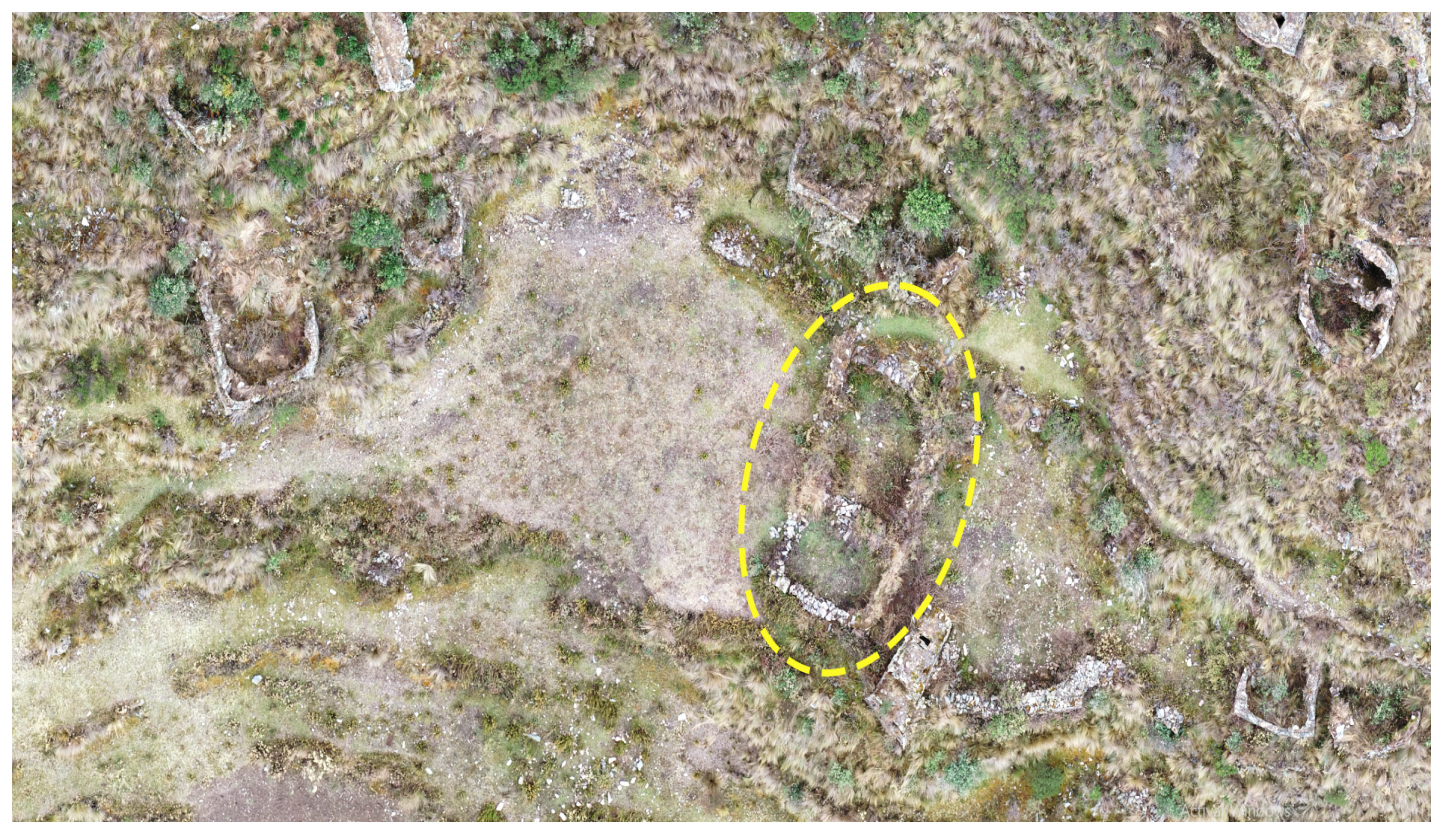

Figura 11: Estructura rectangular de grandes dimensiones (en color amarillo) asociada a un espacio abierto. 


\section{Galerías}

Al realizar el registro arquitectónico en el asentamiento, hallamos una peculiar estructura en el sector A, de planta rectangular, con orientación de este-oeste, de $1.33 \mathrm{~m}$ de alto, $2 \mathrm{~m}$ de ancho y $7.10 \mathrm{~m}$ de largo (ver Figura 12, 13 y 14). Su material constructivo es a base de piedras y argamasa, y para el techo se usaron enormes lajas, que se ha conservado solo en una sección.

Estructuras parecidas fueron reportadas en el sitio arqueológico Rapayán, siendo denominadas como galerías. Han sido construidas sobre el suelo, con accesos de ingreso y salida, con presencia de nichos en sus muros interiores. A razón de ello, por su "hermetismo", se ha señalado que son depósitos (Mantha y Malca, 2004).

Es notable la similitud entre las estructuras reportadas en Rapayán y Huata, solo que, en este último, quizá debido a la mala conservación que presenta, no se identificaron nichos. Sin embargo, en el sector B, se identificaron otras dos posibles galerías, que de largo no excede los $3 \mathrm{~m}$, pero sí poseen nichos en su paramento interior. En todos los casos, estas posibles galerías, están asociadas a viviendas.

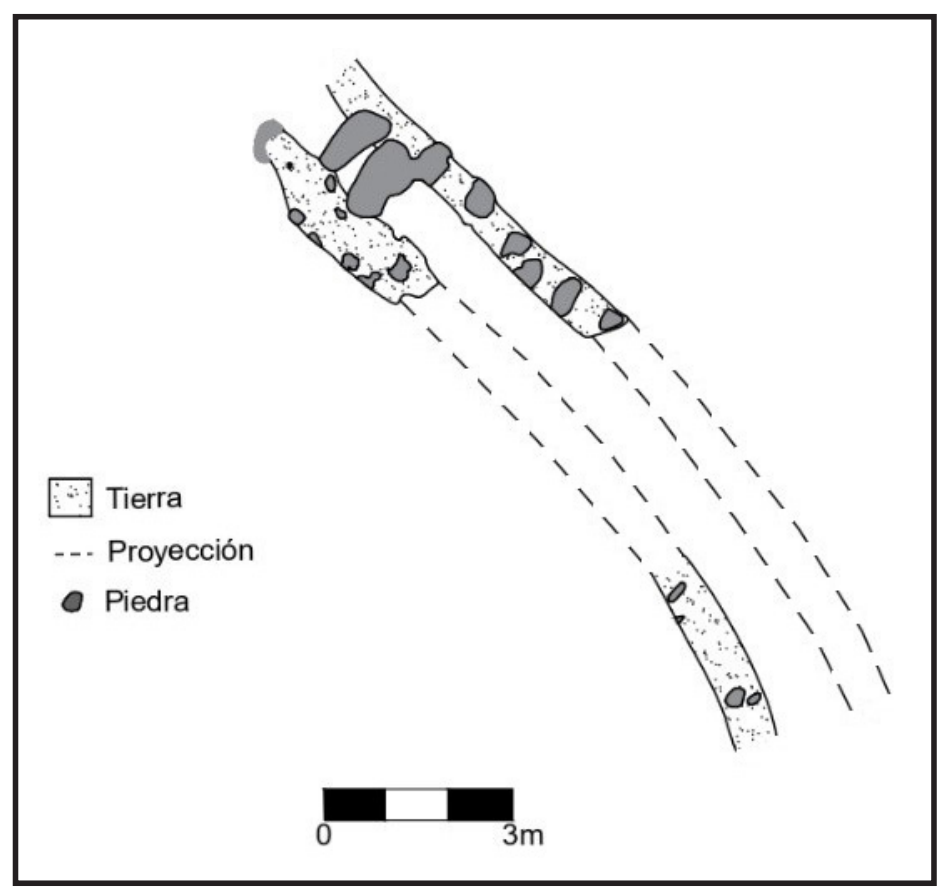

Figura 12: Dibujo de planta de la galería registrada en el sector $A$. 


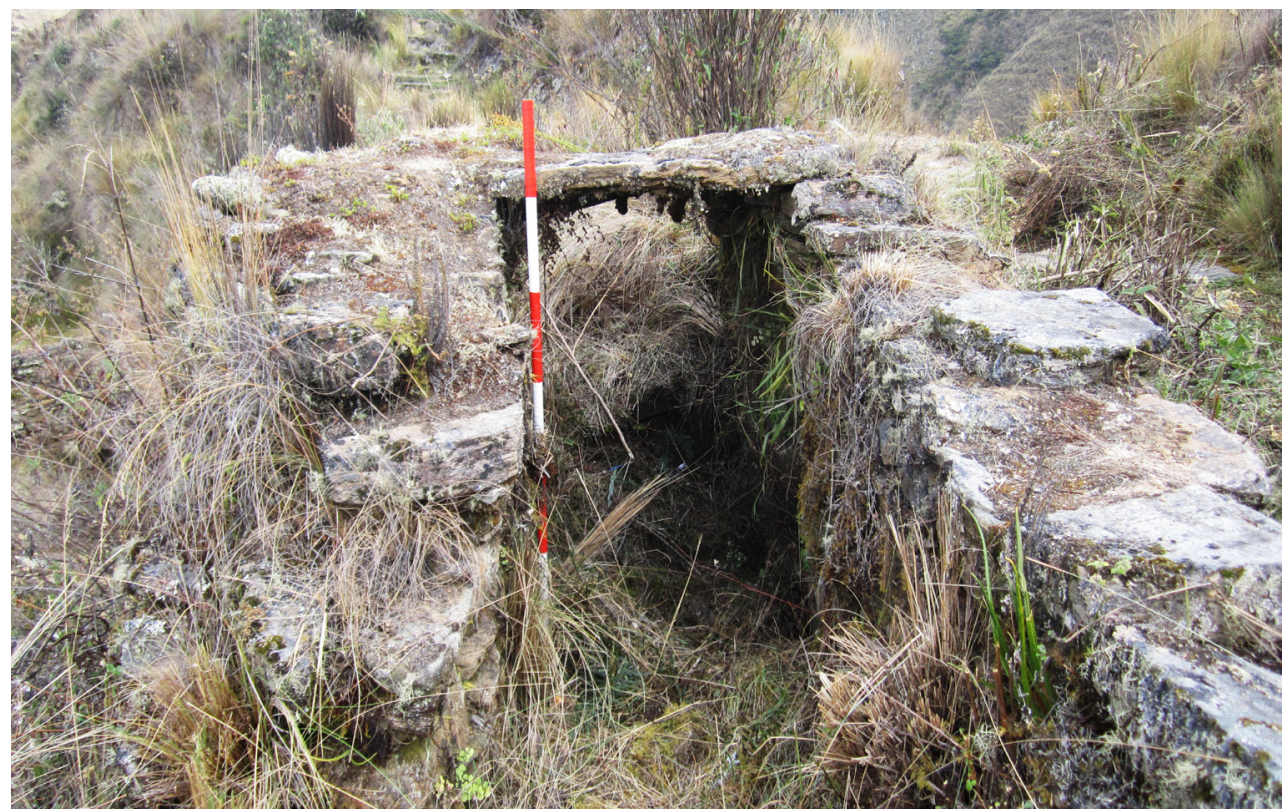

Figura 13: Vista sureste de la galería registrada en el sector $A$.

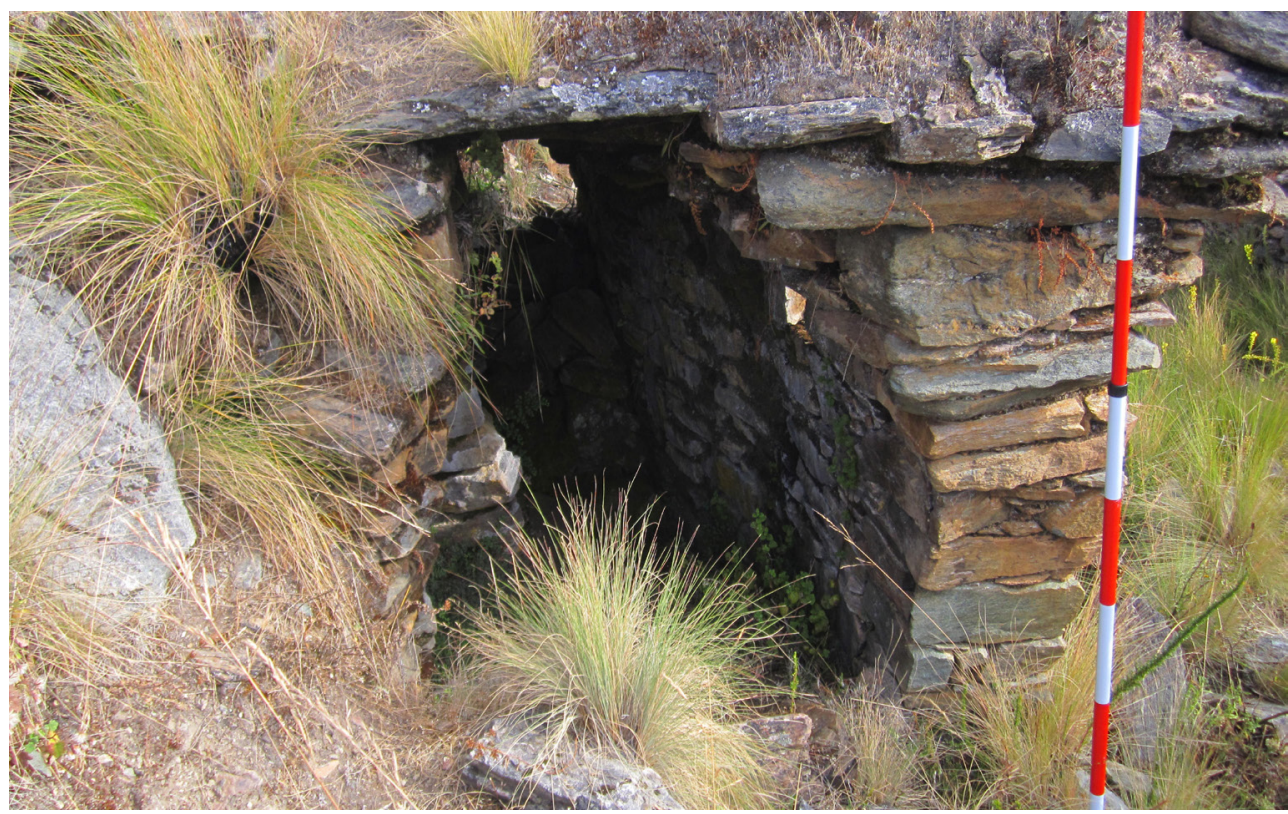

Figura 14: Detalle de otra galería registrada en el sector $B$ 


\section{Murallas}

Durante el período Intermedio Tardío existieron constantes conflictos sociales, evidenciados en la construcción de asentamientos fortificados (Arkush y Stanish, 2005), donde los pobladores pugnaban por acceder a mejores tierras, pastizales y fuentes de agua; razón por la cual los asentamientos de ese período se protegían con murallas y zanjas.

En Tantamayo, Bonnier (1981) registra murallas que rodean los asentamientos, así como en sitios como Isog, donde identifica murallas concéntricas. Por otro lado, Mantha y Malca, también encuentran murallas en Rapayán, pero a diferencia de Tantamayo, estas estructuras más que una función defensiva, habrían tenido una función "funeraria y religiosa", debido a que la protección era parcial y se concentraba más en las torres funerarias (2004, p. 487).

El sitio cercano a Huata, Carhua, posee al noreste una muralla defensiva, que rodea lo que se consideraría la parte más vulnerable del asentamiento y, además, esta reforzada con una zanja que se dispone paralela a la muralla. Otro sitio, al noreste, Winak también se encuentra completamente amurallada. Claramente notamos que los habitantes de esta zona se esmeraron en la construcción de un sistema defensivo.

Luego de examinar los casos mencionados, efectivamente, se ha registrado restos de murallas en Huata, pero no en las periferias, sino al interior del asentamiento, delimitando a los sectores A y B (ver figura 15), que configuran dos espacios sociales bien diferenciados, a modo de barrios. Debido a estas características es muy probable que las murallas, en vez de tener un carácter defensivo, hayan tenido un carácter simbólico, ya que definen los límites de un espacio social respecto de otro dentro de un mismo asentamiento.

Otro dato adicional e interesante es que estas murallas contienen cámaras funerarias o en su defecto están asociadas a espacios funerarios. Los trabajos de Parsons, Hastings y Matos (2004) en asentamientos de las provincias de Junín y Tarma muestran que la combinación de murallas y tumbas en los bordes, podrían ser indicadores de diferencia social. Para el caso de Huata, indicaría la clara diferenciación de dos grupos sociales o ayllus dentro de un mismo asentamiento.

Lo señalado, no excluye que hayan existido murallas defensivas que se pueden haber perdido con el paso del tiempo. Al respecto, Antonio Raimondi nos da ciertas luces, ya que al momento de su visita describe a Huata como un asentamiento fortificado y una de sus razones es porque por un lado hay un "barranco cortado a pico y defendido por muralla de la cual todavía se ve restos" (1901[1860], p. 303). 


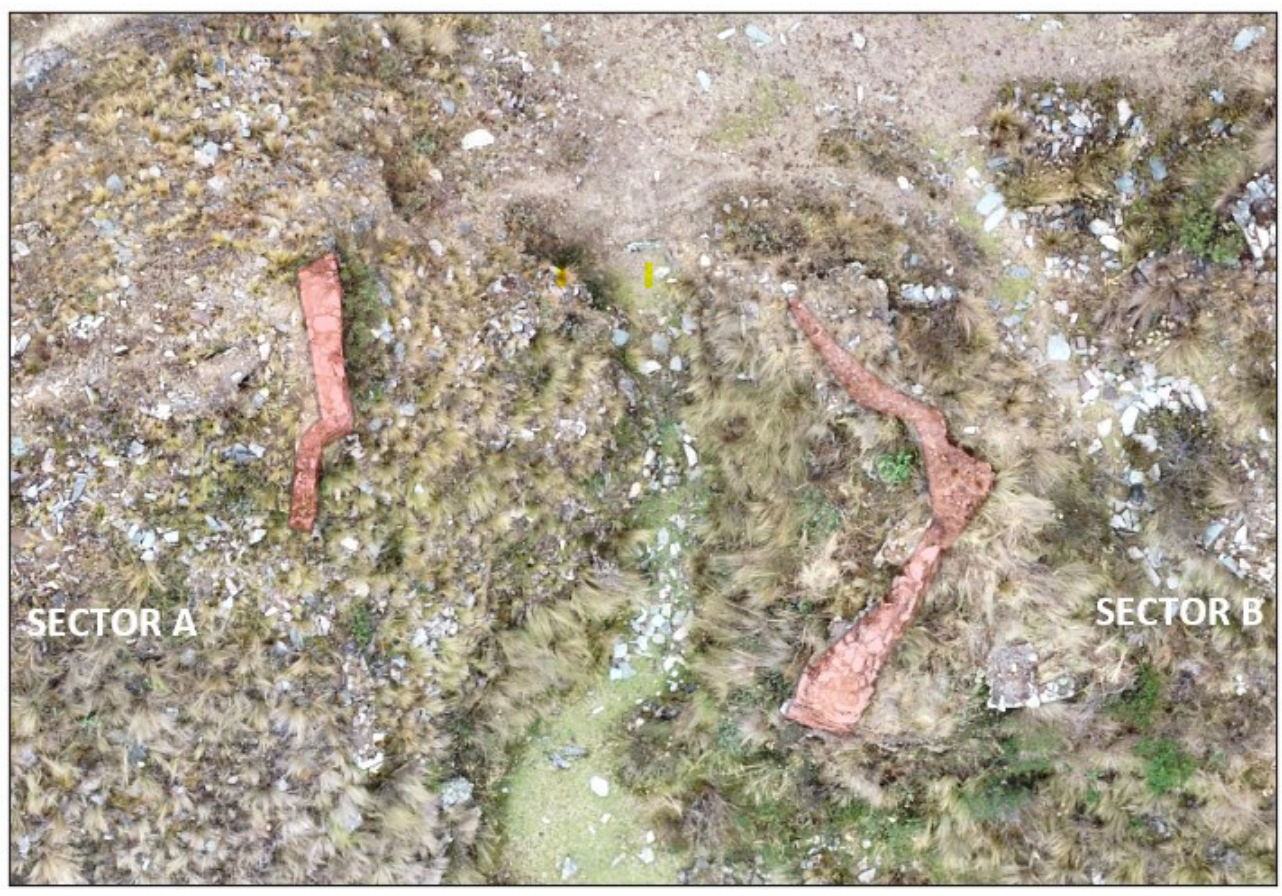

Figura 15: Vista en planta de restos de murallas (sombreado en color rojo), las cuales dividen los sectores $A$ y $B$ del sitio arqueológico Huata.

\section{Estructuras coloniales}

Se trata de dos construcciones aisladas de planta rectangular, ubicadas en las terrazas de la parte baja del asentamiento (sector C). Una de ellas mide $15 \mathrm{~m}$ de largo por $7.2 \mathrm{~m}$ de ancho, destaca porque su muro posterior posee hastial y sus muros laterales se proyectan más de medio metro respecto a la fachada. Además, cuenta con un acceso donde uno de sus lados tiene doble jamba, posicionada de manera inversa a la inca, es decir, con la jamba más angosta hacia el exterior y la ancha hacia el interior (ver figura 17).

Fue edificado probablemente por los mismos pobladores de Huata, quienes usaron materiales y técnicas constructivas locales; sin embargo, se observa sus acabados más burdos y con mayor proporción de argamasa, quizá debido a su rápida construcción. Sus características formales singulares y su ubicación periférica, indicio de su posterior ocupación, sugieren que se trata de una estructura colonial. Un dato interesante, y que apoya nuestro estudio, es su toponimia, ya que los lugareños lo denominan Iglesiapampa, que significa llanura o explanada de la iglesia. La presencia de estas estructuras coloniales es usual en los asentamientos tardíos, como consecuencia de una ocupación colonial temprana en la zona. 

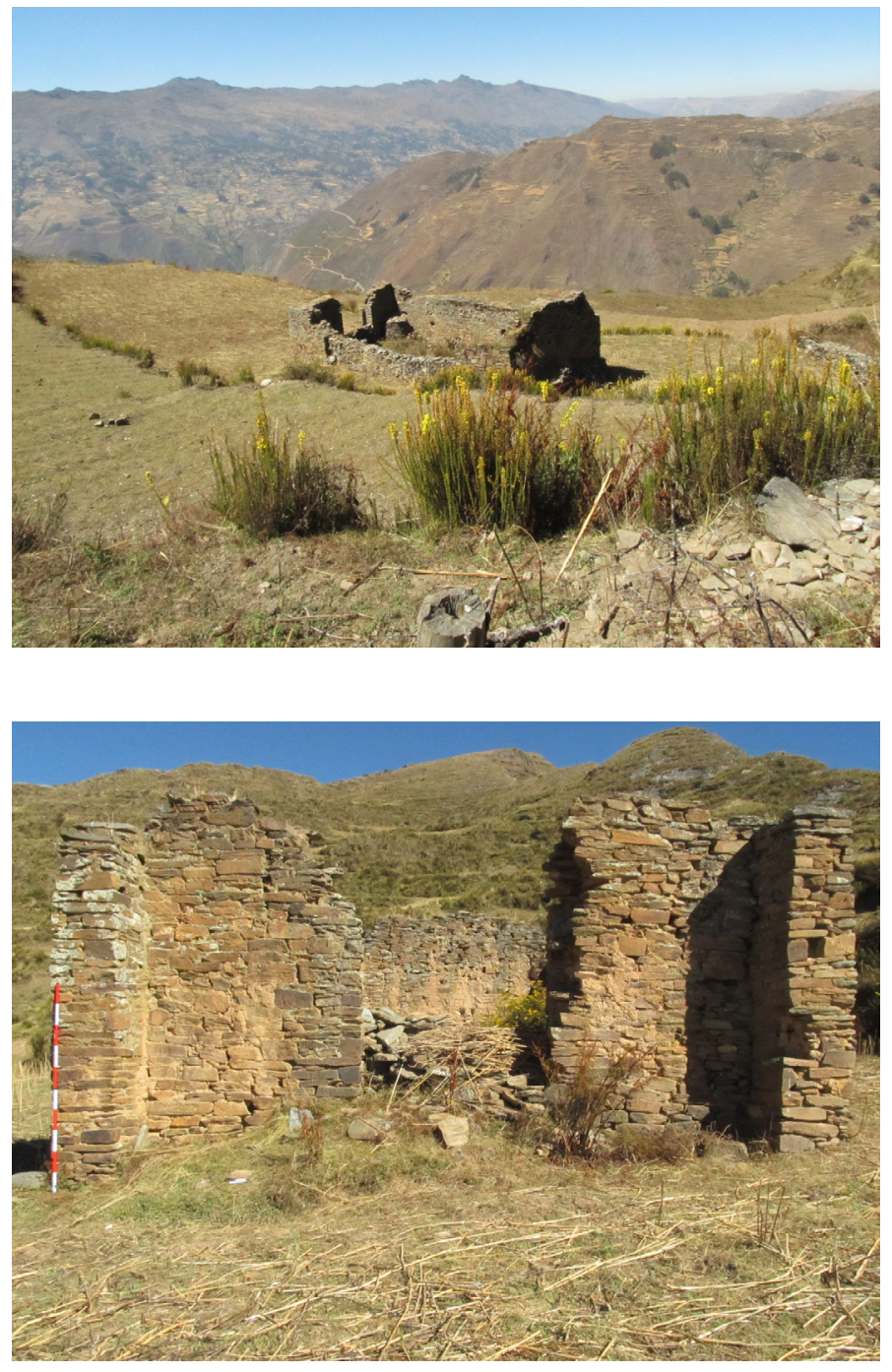

Figura 16. Estructura colonial aislada (iglesiapampa), ubicado en el sector $C$.

Figura 17. Fachada de la estructura colonial (Iglesiapampa).

\section{DISCUSIÓN}

\subsection{Cronología}

Las investigaciones previas realizadas en la zona de estudio, han tenido entre uno de sus objetivos establecer la antigüedad de las ocupaciones en los asentamientos. Entre estos trabajos se encuentran los aportes de Bonnier, Zegarra y Tello (1985) y Mantha y Malca (2016), en la parte norte del Alto Marañón como son los valles de Tantamayo y Rapayán, respectivamente. Para este último se ha planteado una ocupación continua, desde el Período Inicial hasta la época colonial temprana; mientras que, para Piruro en Tantamayo abarca desde el Período Precerámico hasta el Período Inicial, con un abandono posterior de más de 1000 años para nuevamente ser 
ocupado en el Intermedio Tardío hasta inicios de la colonia. Para la zona sur del Alto Marañón, faltan mayores datos, solo para el sitio arqueológico Garu, Salcedo (2012) señala que tiene una ocupación en el Período Precerámico, posterior a ello aparentemente no hay evidencia de su funcionamiento hasta el Horizonte Medio, a partir del cual es habitada hasta el Horizonte Tardío.

De lo expuesto se desprende la siguiente interrogante ¿Huata tiene una ocupación larga y continua como Rapayán o, por el contrario, se trata de un asentamiento con una ocupación más tardía? La revisión de una visita realizada en el año 1549 permite señalar que Huata se encontraba en pleno funcionamiento aquel año, lo cual, sumado a la presencia de arquitectura claramente hispana nos lleva a inferir su ocupación colonial temprana. Este resultado se ratifica con los reportes de otros asentamientos, que dan cuenta que aún seguían poblados tras la presencia temprana de los hispanos en la zona, tal es el caso de Piruro, Rapayán, Garu o Chiquia (Salcedo, 2012; Bonnier 1981).

Además, en el mismo documento de 1549, los entrevistados por La Serna y Espinoza, no solo daban cuenta de sus actividades económicas durante la colonia temprana, sino que detallaron como era en el tiempo de los incas. Estas referencias nos llevan a sostener que la población de Huata, al igual que los asentamientos vecinos, integró también el vasto territorio que conformaba el Tawantinsuyu; por lo que seguramente debían otorgar su fuerza laboral y algunos recursos a beneficio del estado inca. Sin embargo, los trabajos de campo realizados hasta el momento, si bien no permiten señalar que hubo una ocupación directa en el sitio, la ocupación inca pudo darse de manera indirecta, es decir, a través de jefes locales que disponían la mano de obra y recursos locales a favor de los cusqueños.

Lo afirmado hasta aquí, va acorde con los resultados de los estudios realizados en otras zonas, donde se propone que los incas se establecieron solo en sitios estratégicos, motivados por factores medioambientales, de visibilidad y recursos preciados (Hyslop, 2016). Para el valle del Huallaga, por ejemplo, se ha señalado que la administración inca no se estableció en las aldeas, por ello difícilmente se hallan evidencias arqueológicas que reflejen dicha presencia (Grosboll, 1993:54); es así que en lugares donde no despertaban su interés, los incas se conformaban con una ocupación indirecta, como habría sucedido en Huata.

Otro elemento que nos permite inferir en la cronología, es la arquitectura, un componente muy característico que define, en cierta medida a los grupos que habitaron esta zona. Se trata de los edificios de varios pisos, de carácter funerario, que llamó la atención desde tiempos coloniales debido a su monumentalidad. Los trabajos de Bonnier (1981, 1983 y 1985), Rozenberg (1983) y Girault (1981) en Piruro, que, mediante fechados radiocarbónicos, el control de la estratigrafía y su correlato con material cerámico, sumado a trabajos similares realizados por Mantha (2015) 
y Mantha y Malca $(2004,2017)$ en Rapayán, han permitido datarlos para el período Intermedio Tardío. A partir de estas afirmaciones y la comparación con la arquitectura funeraria (edificio de varios pisos) de Huata y los sitios mencionados, se ha logrado evidenciar una gran similitud en los diseños arquitectónicos y en las técnicas constructivas, que nos llevan a proponer su contemporaneidad, ubicándolo en el período Intermedio Tardío.

Todo lo mencionado nos permite sostener que uno de los sitios en la margen izquierda del Marañón, Huata, tiene una ocupación desde el Intermedio Tardío hasta la colonia temprana. Siendo probable su abandono en el año 1572, año en que el virrey Toledo dispuso la política de las reducciones. Esto es confirmado años más tarde, cuando Toribio de Mogrovejo (Angulo 1921[1593]), que, en una de sus tantas visitas pastorales, inspecciona los pueblos de la zona, pero no visita Huata, probablemente porque este ya no se encontraba en funcionamiento.

\subsection{Arquitectura:}

La gran variabilidad arquitectónica existente en Huata es un reflejo de sus diversas y complejas prácticas sociales, resultado de su proceso histórico que abarca una ocupación prehispánica e inicios del período colonial.

A partir de los datos presentados se propone que Huata es principalmente un asentamiento habitacional, conformado en un $70 \%$ por viviendas, lo cual es usual para el área de estudio (Salcedo, 2012; Grosboll, 1993; Morales, 1984; Bonnier, 1981); sin embargo, la presencia de un tipo de viviendas conocidas como "casa Rapayán", de planta rectangular con división interna, únicamente reportadas en el sitio arqueológico Rapayán, representa un caso atípico, por lo que Alexis Mantha (2015) ha sugerido que posiblemente Huata haya sido un asentamiento bi-etnico. Esta propuesta resulta interesante a la luz de trabajos como el de Duviols (1973) sobre los grupos sociales huari y llacuaz (agricultores y pastores), donde los pastores se instalaban en asentamientos de los agricultores, ya que estos ocupaban pisos ecológicos intermedios o fronterizos, es decir, con acceso a punas y a las tierras bajas cultivables. Estas condiciones presentes en Huata resultan sugerentes, sin embargo, faltan datos de excavaciones que refuercen dicho planteamiento.

Además de las viviendas, se ha registrado un $22 \%$ de estructuras funerarias, en los sectores A y B, conformadas por chullpas y edificios de varios pisos que son similares a las reportadas en Tantamayo y Rapayán, por lo que se asume su contemporaneidad y su funcionalidad funeraria. Por su monumentalidad y ubicación estratégica, al centro de cada sector, asociados en algunos casos a grandes espacios abiertos, permite señalar la importancia de los malquis o ancestros fundadores colocados en estos edificios para ser exhibidos a un grupo mayor, quizá toda la aldea, dándose así una suerte de interacción entre los difuntos y los vivos. En el caso 
de las chullpas, estos están emplazadas en los extremos de cada sector del sitio arqueológico, asociados a pequeños espacios abiertos, por lo que se considera que eran visitados por grupos de parentesco a estos espacios funerarios de relación interfamiliar. Es conveniente indicar que Mantha (2015) propone que las viviendas de planta en $\mathrm{D} u$ ovaladas de Huata posiblemente albergaban momias en nichos colocados sobre los muros de las casas, estableciéndose un culto a nivel familiar y de carácter más íntimo. Estas tres formas de prácticas funerarias están presentes en la gran mayoría de sitios tardíos ubicados en la inter-cuenca del río Marañón (Pinilla y García, 1981; Ravines, 1984; Morales, 1984; Mantha, 2009; Onofre, 2012; Salcedo, 2012). La importancia que se le daba al cuidado y a los rituales dedicados a los ancestros tanto en las viviendas, chullpas y los edificios funerarios nos sugieren que estos pueblos tenían no solo una especial devoción a sus ancestros, sino también una jerarquía de cultos, a nivel familiar, intrafamiliar y comunal. Situación similar se reporta en Rapayán, Áncash (Mantha, 2006). Entender el porqué de estas racionalidades es complejo, sin embargo, resulta interesante lo observado por Gil (2002:60), quien refiere que "los antepasados definen a la comunidad, le confieren identidad, legitiman su posesión de tierras y recursos y protegen a sus miembros de la injerencia externa". Señala, además, que el compartir alimentos y bebidas entre los miembros vivos de la comunidad y los bultos funerarios reproduce una suerte de reciprocidad y redistribución entre ellos (Gil, 2002). Dicho de otro modo, el cuidado de los muertos genera bienestar y abundancia para los vivos. Quizá esto explique, en parte, la importancia que se les daba al cuidado y culto a los ancestros.

Continuando con los tipos arquitectónicos registrados, en menor proporción, hemos identificado galerías (2\%), murallas (2\%), edificios rectangulares ( $2 \%$ y finalmente arquitectura colonial (2\%); demostrando así la gran variedad arquitectónica en todo el asentamiento. De todas estas, solo las galerías se han identificado en Winak y Rapayán, no hay reportes en otros sitios.

Todos estos componentes arquitectónicos, excepto las estructuras coloniales, se distribuyen en los sectores A y B de Huata, lo cual, ha permitido identificar una organización arquitectónica similar en cada una. Siguiendo una orientación este-oeste, al iniciar el sector A se ubican las viviendas, luego las estructuras funerarias en la zona central, para nuevamente encontrar viviendas y una concentración de chullpas al final del sector. Esta configuración espacial parece repetirse en el sector B (ver Figura 18).

Esa disposición hace pensar en un asentamiento dividido en dos espacios sociales independientes, con una posible organización dual. Esta forma de configuración no sería inusual en el mundo andino, ya que hay estudios como en la región Tarama-Chinchaycocha donde se han reportado asentamientos con estas caracterís- 


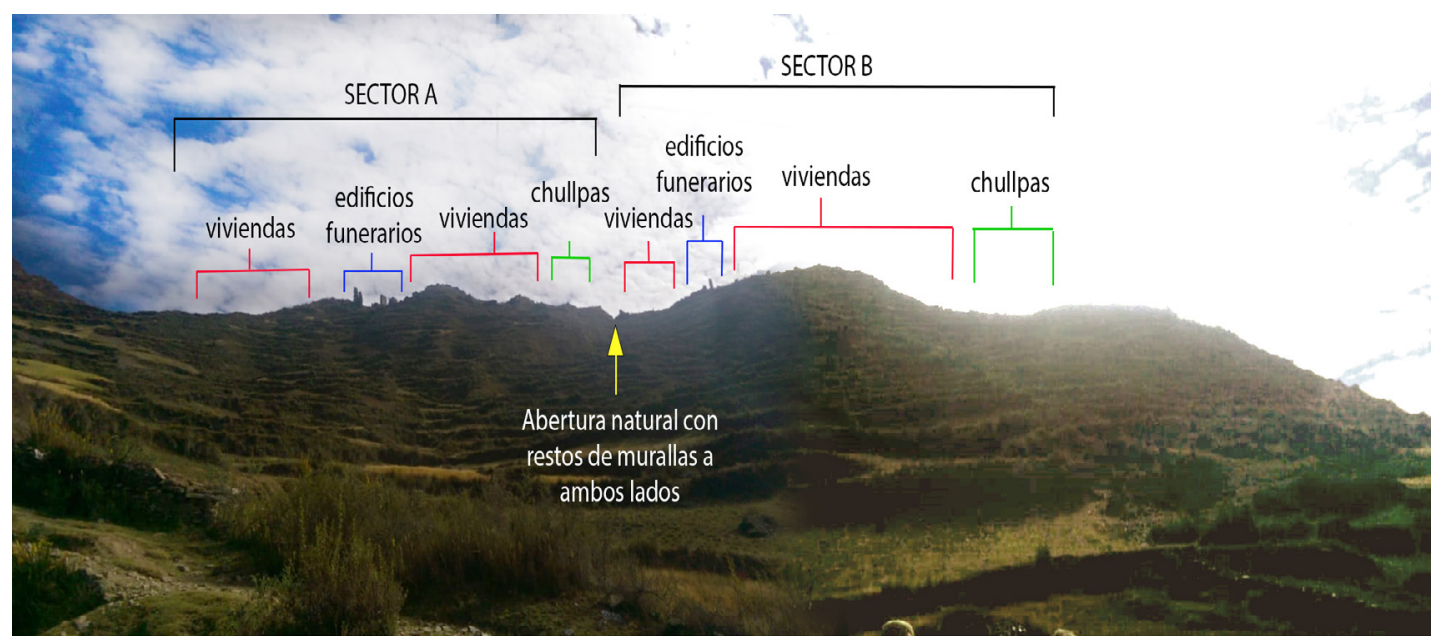

Figura 18. Configuración espacial de forma dual, evidenciada en la disposición similar de las diversas estructuras en los sectores A y B de Huata.

ticas duales (Parsons, Hastings y Matos, 2004). O, los reportados en Apurímac, en los sitios de Toroyuy, Inkawasi Quchapata, donde se han registrado pares de asentamiento, formando un patrón bi-partito (Moore 1995 y Palomino, 1971 citados en Saintenoy, 2016). Al respecto, Bauer (1987, p. 198) señala que los ayllus a pesar de tener independencia económica "deben ser comprendidos en relación con una comunidad dualística más grande de la cual formaban partes segmentarias". Agrega, además, que "la presencia de mitades en toda el área andina, definida de una manera indígena por contrastes binarios con rangos internos y jerárquicos (alto: bajo, hombre: mujer, derecha: izquierda), otorga credibilidad a la gran antigüedad de este principio de estructuras" (1987, p. 200). Incluso hasta nuestros días, muchos pueblos de la región andina presentan un sistema de mitades en su organización social, la cual se manifiesta en dualidades presentes en grupos de dos y cuatro barrios (Palomino, 1971).

Finalmente, la existencia de monumentales edificios funerarios, inexistentes en los asentamientos vecinos como Costalperga, Carhua y Winak, indicaría una mayor jerarquía ¿Se tratará acaso de la sede de un antiguo linaje de líderes locales que tuvo bajo su control a los asentamientos vecinos? En caso del valle de Huallaga se sabe que los curacas pueden haber dirigido una o varias aldeas, y, posiblemente, esta organización se haya mantenido de forma similar en los períodos del Intermedio Tardío y Horizonte Tardío, ya que al no haber una presencia inca directa no habría significado mayores cambios en su patrón de asentamiento, tal como sucedió en los asentamientos reportados por Grosboll (1993) en el valle del Huallaga. 


\section{CONCLUSIONES}

Los resultados de las investigaciones permiten proponer que el sitio arqueológico Huata tiene una ocupación continua desde el Período Intermedio Tardío hasta la colonia temprana, y se deshabitó en el año 1572, debido a las políticas reduccionistas del virrey Toledo. Sin embargo, aún falta definir su ocupación anterior al Intermedio Tardío, considerando que los asentamientos del área, como Rapayán, cuentan con una ocupación sucesiva que va desde el Período Inicial hasta la Colonia, de la misma manera que Piruro en Tantamayo, que tiene una ocupación discontinua, pero bastante larga que inicia en el Período Precerámico.

En cuanto a la arquitectura, se ha identificado una gran variabilidad como viviendas, galerías, estructuras funerarias, murallas, estructuras coloniales (iglesia) y estructuras rectangulares cuya función aún desconocemos; pero podrían tratarse de viviendas de jefes locales, que adoptaron patrones foráneos para distinguirse del resto de la población, debido a que este tipo de planta y ubicación estratégica junto a espacios abiertos así lo sugieren. Cabe mencionar que entre estos tipos arquitectónicos destacan los monumentales y, estratégicamente bien ubicados, edificios funerarios de varios niveles, que no solo eran moradas de los mallquis, sino también fueron el reflejo de un grupo social complejo y muy organizado que aparentemente poseía una mayor jerarquía respecto a los sitios vecinos.

Estos tipos arquitectónicos identificados se distribuyen de forma similar en los sectores A y B, donde cada una cuenta con estructuras domésticas, edificios de varios pisos y sus propias áreas funerarias. Configuración que lleva a pensar en espacios sociales independientes, a modo de barrios, cuya naturaleza estaría reflejando una organización dual del asentamiento, característica de muchos pueblos durante el período prehispánico.

Asimismo, el estudio de la arquitectura permite dilucidar que Huata es un asentamiento donde no se manifiesta la ocupación inca de forma directa, ya que durante los trabajos de campo realizados no se identificó arquitectura de patrón cuzqueño como ha ocurrido en otros asentamientos del Alto Marañón.

Finalmente, debemos señalar que las conclusiones a las que se ha llegado son aproximaciones a partir de un estudio superficial del sitio arqueológico complementado con datos etnohistóricos que se manejan para la zona; por ello, es necesaria la evaluación de estas propuestas con futuras excavaciones en el lugar.

Agradecimientos: Agradecemos a la Municipalidad Distrital de Singa y a su entonces alcalde Celestino Collazos por confiar en este trabajo y brindarnos su apoyo. A nuestros colegas y amigos Gonzalo Irureta y Xiomara Palacios por su gentil ayuda en el registro arqueológico. Del poblado de Bellas Flores agradecemos a Percy Collazos 
y Shaulin Espinoza por el apoyo en los trabajos de campo. De igual manera, por los comentarios al texto agradecemos a Carlo José Ordóñez, Luis Flores, Jesús Maza y James Quillca. Por último, y no por ello menos importante, a nuestras familias, por la constante motivación y la ayuda que nos ofrecieron en todo momento, en especial a quien en vida fue Joe Klever Romero Collazos, para quien este trabajo es un pequeño homenaje.

\section{REFERENCIAS BIBLIOGRÁFICAS}

Amat, H. (2013). El imperio Yaro y la expansión militarista de los Estados Regionales. Cien años de la arqueología en la sierra de Áncash, Bebel Ibarra (editor). Instituto de Estudios Huarinos, Huari, p. 469-498.

Angulo, D. (1921). Libro de Visitas, 1593. Diario de la segunda visita pastoral, que hizo de su Arquidiócesis el ilustrísimo señor don Toribio Alfonso de Mogrovejo, arzobispo de los Reyes. Revista del Archivo Nacional, Tomo II, entrega 1 p. 37-78.

Arkush, E. y Stanish, C. (2005). Interpreting conflict in the ancient Andes. Current Anthropology 46, pp. 3-28.

Bauer, B. (1987). Sistemas andinos de organización rural antes del establecimiento de reducciones: El ejemplo de Pacariqtambo (Perú). Revista Andina 9, Año 5, N¹ (Julio), pp. 197-209.

Bonnier, E. (1981). Las ruinas de Tantamayo: Vestigios de una ocupación tardía. Boletín de Lima 14, año 3.

Bonnier Howard, E., Kaplan, R., Rozenberg, C. (1983). Recherches archéologiques, paléobotaniques et ethnolinguistques dans une vallée du Haut Marañón (Pérou): le Projet Tantamayo - Piruru. Boletín del Instituto Francés de Estudios Andinos Tomo XII (1-2), pp. 103-133. Lima.

Bonnier, E., Zegarra, J. y Tello, J. C. (1985). Un ejemplo de crono-estratigrafía en un sitio con superposición arquitectónica: Piruru-unidad I/II. Boletín del Instituto Francés de Estudios Andinos 14(3-4): 80-101.

Bonnier, E. y Rozenberg, C. (1987). El proyecto Tantamayo Piruro. Arqueología en el valle Alto del Marañón. Kuntur $N^{\circ}$ 3, p. 1-9. Lima.

Buikstra, J. y Ubelaker, D. (1994). Standards. For data collections from human skeletal remains. Arkansas archeological survey research series, $\mathrm{N}^{\circ} 44$. USA.

Cerrato, E. (2011). La prospección arqueológica superficial: Una técnica no destructiva para una ciencia que sí lo es. Arte, Arqueología e Historia, 18, pp. 151 - 160. España. 
Duchesne, F. y Chacama, J. (2012). Torres funerarias prehispánicas de los Andes centro-sur: muerte, ocupación del espacio y organización social. Estudio comparativo: Coporaque, cañón del Colca (Perú), Chapiquiña, precordillera de Arica (Chile). Chungara 44(4), 605-619

Duviols, P. (1973). Huari y Llacuaz. Agricultores y pastores. Un dualismo prehispánico de oposición y complementariedad. Revista del Museo Nacional, Tomo XXXIX, pp. 153-191, Lima.

Espinoza, W. (2004). Ichoc Huánuco y el señorío del curaca Huanca en el reino de Huánuco siglos XV y XVI. II Forum Huamalíes: Cultura, Historia y Perspectivas. Lima: Universidad Nacional Federico Villareal, p. 87-164.

Flornoy, B. (1957). Monuments de la región de Tantamayo. Journal de la Socièté des Americanistes, Tomo XLVI, p. $207-225$.

Gil, F. (2002). Donde los muertos no mueren. Culto a los antepasados y reproducción social en el mundo andino. Una discusión orientada a los manejos del tiempo y el espacio. Anales del Museo de América, N¹0, p. 59-83. Madrid.

Girault, L. (1981). Fouilles sur le site de Piruro en 1968 et 1970. Bulletin de l'Institut Francais d'Etudes Andines, Tomo X (1-2), pp. 101-102. Lima.

Grosboll, S., (1993). And he said in the time of the Ynga, they paid tribute and served the Ynga. Provincial Inca (pp. 44-76). M. Malpass (ed.). Iowa City: University of Iowa Press.

Herrera, A., Amaya, A. y Aguilar, M. (2012). Una aproximación tipológica y funcional a la arquitectura indígena de los siglos IX al XVI en la Sierra de Áncash. Arquitectura prehispánica tardía: construcción y poder en los Andes centrales, Lane K.-Luján M. (eds.), Universidad Católica Sedes Sapientiae, Fondo Editorial, Lima, p. 165-218.

Hyslop, J. (2016). Asentamientos Planificados Inka. Lima: Petróleos del Perú.

Ibarra, B., (1999). Investigaciones arqueológicas en el Alto Marañón (Provincia de Huari-Ancash). Boletín del Museo de Arqueología y Antropología, Universidad Nacional Mayor de San Marcos, p. 6-12.

Ingham, J. (2019). Sitios Yarowilca del Alto Marañón, Perú. Imágenes de visitas realizadas en 1996 y 2015 a 2018. https://www.academia.edu/41057548/Sitios_Yarowilca_del_Alto_Mara\%C3\%B1\%C3\%B3n_Per\%C3\%BA

Kesseli, R. y Pärssinen, M. (2005). Identidad étnica y muerte: torres funerarias (chullpas) como símbolos de poder étnico en el altiplano boliviano de Pakasa (1250-1600 d. C.). Bulletin de l'Institut Francais d'Études Andines, 34 (3): 379-410, Lima: Instituto Francés de Estudios Andinos. 
Krenzer, U. (2006). Compendio Completo de Métodos Antropológico Forenses. Centro de análisis forense y ciencias aplicadas. Guatemala.

Mantha, A. (2015). Houses, residential burials, and identity in the Rapayán valley and the upper Marañón drainage, Perú, during late Andean prehistory. Latin American Antiquity 26(4), p. 433-451

Mantha, A. (2013). Shifting Territorialities under the Inka Empire: The Case of the Rapayán Valley in the Central Andean Highlands. Archeological papers of the American Anthropological Association, 22(1), 164-188.

Mantha, A. (2009). Territoriality, social boundaries and ancestor veneration in the central Andes of Peru. Journal of Anthropological Archaeology 28, pp. 158-176.

Mantha, A. y Malca, H., (2004). El sitio de Rapayán y su diversidad arquitectónica durante los períodos tardíos de la prehistoria andina. Arqueología de la Sierra de Ancash: Perspectivas y Propuestas, Ibarra, B. (Ed.), Segunda ed. Instituto Cultural Runa, p. 467-488. Lima, Perú.

Mantha, A. y Malca, H. (2016). Consideraciones cronológicas en el Alto Marañón: Tantamayo y Rapayán. Arqueología de la Sierra de Áncash 2: Población y Territorio, Ibarra, B. (Ed.) Instituto de Estudios Huarinos, p. 165-178.

Mantha, A. y Malca, H. (2017). Excavaciones en el complejo arqueológico de Rapayán (Áncash, Perú): Resultados e interpretaciones. INDIANA 34(1), p. 95-127.

Mantha, A. (2006). "Late rehispanic social complexity in the Rapayán Valley, upper Marañan drainage, Central Andes of Perú". A. Herrera Wassilowsky, C. Orsini \& K. Lane, (eds.). La complejidad social en la sierra de Áncash: ensayos sobre paisajes, economía y continuidades culturales (pp. 37-64). Milano: Civiche Raccolte d'Arte Applicata del Castello Sforzesco.

Montesinos-Tubée, D. (2016). Diversidad florística asociada a los restos arqueológicos de la cultura Yarowilca en los departamentos de Huánuco y Ancash, Perú. Arnaldoa 23(2), 475-516. http://journal.upao.edu.pe/Arnaldoa/article/ viewFile/669/636

Moore, J. (1996). Architecture ami power in the Ancient Andes. The archaeology of public building. Cambridge University Press.

Morales, D. (1984). Algunos sitios arqueológicos del reino de Guanuco. Boletín de Lima $33, p .87-95$.

Morris, C., y Thompson, D. (1985). Huánuco Pampa: An Inca City and Its Hinterland. Londres: Thames and Hudson. 
Onofre, J. (2012). Los Restos Arqueológicos en el Alto Marañón: Evidencias de una Ocupación de los Guánucos desde el Periodo Horizonte Medio al Intermedio Tardío. Arqueología y Sociedad, 25, 169-184.

Ordóñez, C. y Castro, T. (2015). La capilla Virgen Purísima de Huánuco Pampa: análisis estratigráfico de un edificio del siglo XVIII en los Andes peruanos. Conserva 20, p. 103-120.

Palomino, S. (1971). «La dualidad en la organización sociocultural de algunos pueblos del área andina». Revista del Museo Nacional 37, pp. 231-260. Lima.

Parsons, J., Hastings, C. y Matos, R. (2004). Reconstruyendo el Estado en la Sierra Central del Perú. Investigaciones Sociales, Año VIII, Nº12: 55-98.

Pinilla, J. y García, R. (1981). El valle de Tantamayo: una síntesis histórica. Boletín de Lima, 10, p. 31-43.

Raimondi, A. (1901). Itinerario de los viajes de Raimondi en el Perú. De Tayabamba a Carhuaz (1860). Boletín de la Sociedad Geográfica de Lima, Tomo 10, Nº 7,8 y 9.

Ravines, R. (1984). Tinyash, un pueblo prehispánico de la puna. Boletín de Lima, 7(31), p. 31-37.

Rivero, M. y Tschudi, J. (1851). Antigüedades peruanas. Viena: Imprenta Imperial de la Corte y del Estado.

Saintenoy, T. (2016). Arqueología de las llaqtas del valle del Apurímac: contribución al estudio de la territorialidad de las comunidades aldeanas serranas en los Andes prehispánicos. Chungará, Revista de Antropología Chilena, 48(2), 147-172.

Salcedo, L. (2012). Praehistoria Andina II. La ocupación Wamallí en las cuencas de los ríos Lauricocha, Vizcarra y Alto Marañón, Huánuco. ECOTEC, Lima.

SENAMHI (2011). Evaluación Hidrológica de las Cuencas Amazónicas Peruanas. Ministerio del Ambiente, Perú. https://centroderecursos.cultura.pe/sites/default/ files/rb/pdf/Evaluacion\%20hidrologica\%20de\%20las\%20cuencas\%20amazonicas\%20peruanas.pdf

Serna, M. y Espinoza, J. (2004). Visita del repartimiento del cacique Guanca en la provincia de Guanuco, hecha por el capitán Miguel de La Serna y Juan de Espinoza. Año 1549. II Forum Huamalíes: Cultura, Historia y Perspectivas. Lima: Universidad Nacional Federico Villareal, p. 87-164.

Varallanos, J. (1959). Historia de Huánuco: introducción para el estudio de la vida social de una región del Perú, desde la era prehistórica a nuestros días. Buenos Aires, Argentina: Imprenta López. 
Vázquez, A. (1948) [1628]. Compendio y descripción de las Indias occidentales. Smithsonian Miscellaneous Collections, Vol. 108. Transcrito del Manuscrito original por Charles Upson Clark. Washington.

Weiss P. (1961). Tipología de las deformaciones cefálicas-estudio cultural de los tipos cefálicos y de algunas enfermedades óseas. Osteología Cultural. Practicas cefálicas 2da Parte. Perú.

\section{SOBRE LAS AUTORAS}

\section{Jakeline Romero Rodríguez}

Licenciada en Arqueología por la Universidad Nacional Mayor de San Marcos y Bachiller en Historia por la misma casa de estudios. Actualmente está realizando trabajos de prospección arqueológica en la provincia de Huamalíes (Huánuco). Ha participado en el Monitoreo de afectaciones y procesos de deterioro en el camino inca y sitios arqueológicos asociados del Tramo Huánuco Pampa-Huamachuco del proyecto Qhapaq Ñan (2019), en el Centro Internacional de Investigación, Conservación y Restauración de Chavín (2018) y en el Proyecto de Inversión Pública Zona Arqueológica Huaca Bellavista (2017).

\section{Katia Herrera Ynderique}

Cursante de la Maestría en Ciencias Sociales con mención en Gestión del Patrimonio Cultural de la Universidad Nacional de Trujillo, Licenciada en Arqueología por la Universidad Nacional Mayor de San Marcos. Actualmente es integrante del área de investigación de la Unidad Ejecutora 003 del Ministerio de Cultura - Zona Arqueológica Caral. Ha sido parte del Proyecto de Investigación Arqueológica Cerro El Pacífico - Lima (2016), del Proyecto de Inversión Pública Zona Arqueológica Huaca Bellavista - Lima (2017 - 2018) y del Proyecto de Monitoreo y Rescate Arqueológico Copacabana / CÁLIDDA - Lima (2019 - 2020). 